INEEL/EXT-99-01335

February 2000

\title{
Spent Nuclear Fuel Dry Transfer System Cold Demonstration Project
}

\author{
M. R. Christensen \\ D. C. Koelsch \\ L. Stewart \\ M. A. McKinnon
}


INEEL/EXT-99-01335

\title{
Spent Nuclear Fuel Dry Transfer System Cold Demonstration Project
}

\author{
M. R. Christensen \\ D. C. Koelsch \\ L. Stewart \\ M. A. McKinnon
}

Published February 2000

Idaho National Engineering and Environmental Laboratory Idaho Falls, Idaho 83415

Prepared for the

U.S. Department of Energy

Office of Civilian Radioactive Waste Management and

Assistant Secretary for Environmental Management

Under DOE Idaho Operations Office

Contract DE-AC07-99ID13727 


\begin{abstract}
The spent nuclear fuel dry transfer system (DTS) provides an interface between large and small casks and between storage-only and transportation casks. It permits decommissioning of reactor pools after shutdown and allows the use of large storage-only casks for temporary onsite storage of spent nuclear fuel irrespective of reactor or fuel handling limitations at a reactor site. The DTS prototype demonstration is consistent with the U.S. Department of Energy's (DOE) mandate from Congress in 1991 and 1992 to implement the DOE plan, "Cooperative Demonstration Project for Transportable Storage Systems and Spent Fuel Transfer." The DTS was developed under a cooperative agreement issued by DOE to the Electric Power Research Institute (EPRI) in September 1993. Transnuclear, Inc (TN) subsequently designed the DTS under a contract from EPRI. On the basis of the TN/EPRI design, DOE initiated a cold demonstration of the DTS prototype in August 1996 at the Idaho National Engineering and Environmental Laboratories (INEEL). The major components demonstrated included the fuel assembly handling subsystem, the shield plug/lid handling subsystem, the cask interface subsystem, the demonstration control subsystem, a support frame, and a closed circuit television and lighting system. The demonstration included a complete series of DTS operations from source cask receipt and opening through fuel transfer and closure of the receiving cask.
\end{abstract}

The demonstration included both normal operations and recovery from off-normal events. It was designed to challenge the system to determine whether there were any activities that could be made to jeopardize the activities of another function or its safety. All known interlocks were challenged.

The equipment ran smoothly and functioned as designed. A few "bugs" were corrected. Prior to completion of the demonstration testing, a number of DTS prototype systems were modified to apply lessons learned to date. Additional testing was performed to validate the modifications. In general, all the equipment worked exceptionally well. The demonstration also helped confirm cost estimates that had been made at several points in the development of the system. 


\section{ACKNOWLEDGMENTS}

The authors express their appreciation for the support of the U.S.

Department of Energy, Office of Civilian Radioactive Waste Management and Office of Environmental Management, and the Electric Power Research Institute and its Utility Review Group. We are grateful for Transnuclear's contribution to the design, Fluor Daniel, Inc. for contributing procurement activities, and the staff and management of the Idaho National Engineering and Environmental Laboratory for demonstration testing.

\section{Technical Management Committee}

L. Stewart DOE Headquarters

D. C. Koelsch DOE Idaho Operations

A. Machiels Electric Power Research Institute

M. A. McKinnon Battelle Pacific Northwest Division

\section{Electric Power Research Institute}

R. W. Lambert

R. H. Jones (Consultant)

\section{DOE Idaho Operations Office}

B. A. Beller

Idaho National Engineering and Environmental Laboratory

M. R. Christensen Bechtel BWXT Idaho, LLC

Fluor Daniel, Inc.

W. Becktell

During the course of the demonstration, members of EPRI, DOE-OCRWM, DOE-HQ EM, DOE-YUCCA Mountain Project Office, and the NRC visited the DTS system. 


\section{CONTENTS}

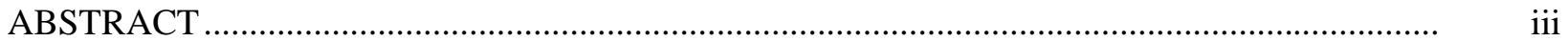

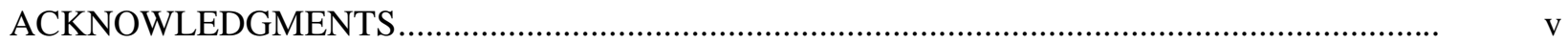

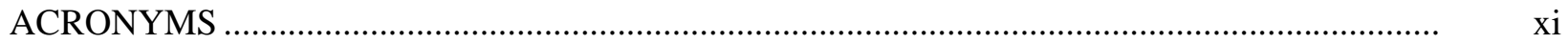



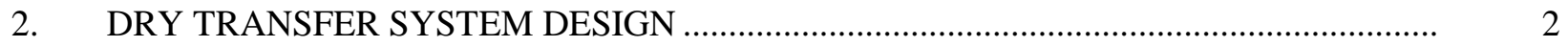

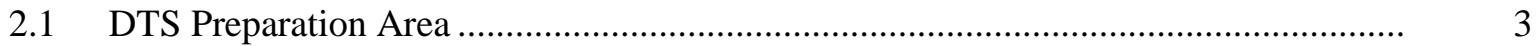

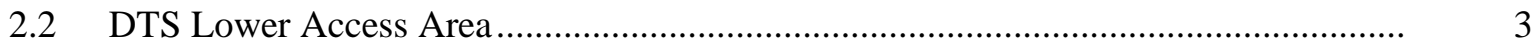

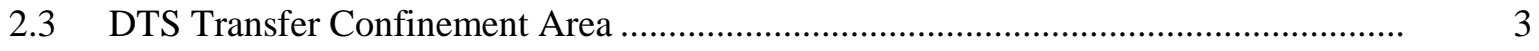

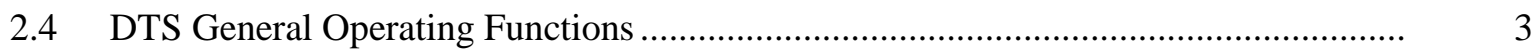

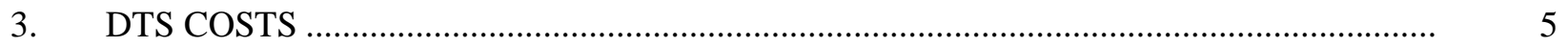

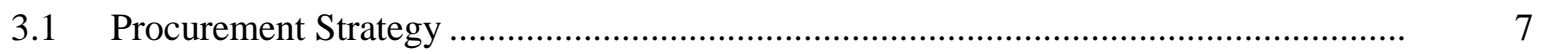

3.2 Quality Assurance Requirements_-Impacts on Costs ........................................... 7

4. TEST PLAN AND DEMONSTRATION PROCEDURES ................................................... 9

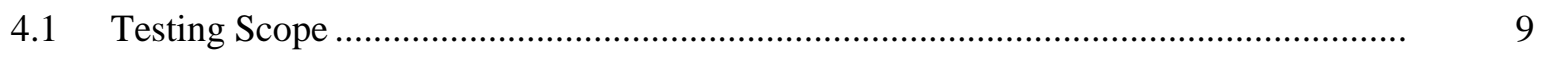

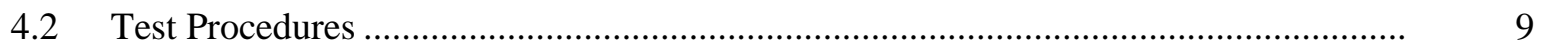

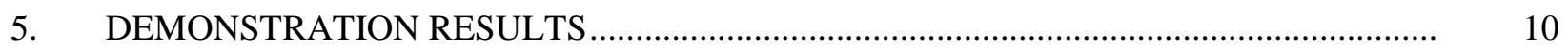

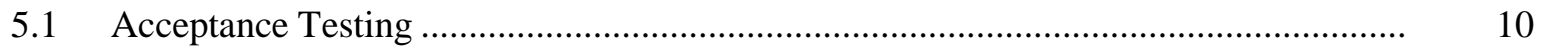

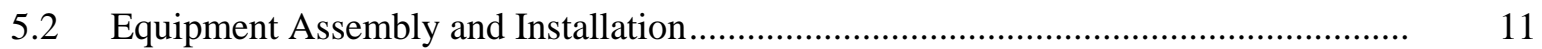

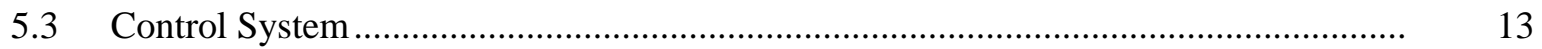



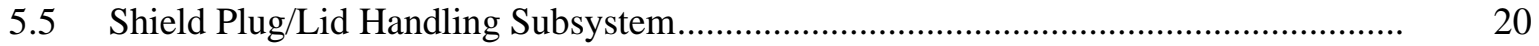

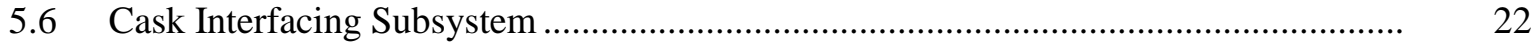

5.7 Closed-Circuit Television Subsystem …............................................................... 24

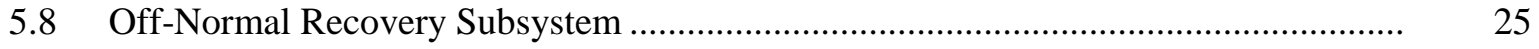

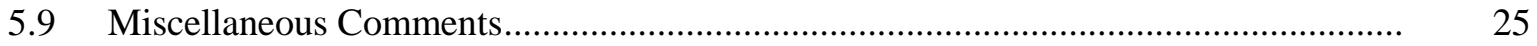


5.10 System Upgrades Resulting from the Demonstration ........................................... 25

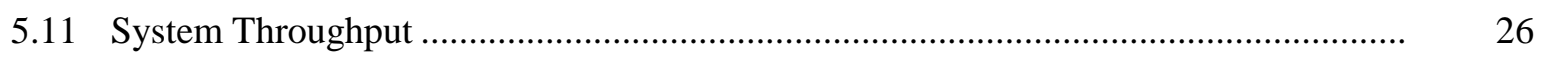

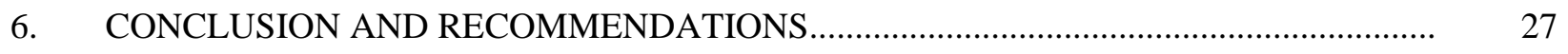

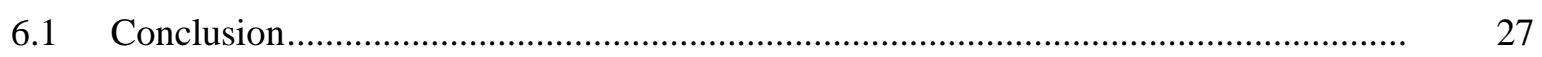

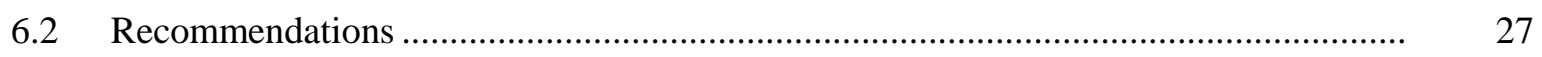

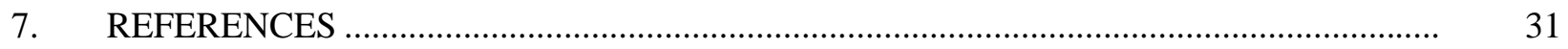

Appendix A-Comparison of DTS Demonstrated at INEEL and the EPRI DTS

Appendix B-Dry Transfer System Demonstration Test Plan

\section{FIGURES}

1. Cross-section of the EPRI conceptual design for a dry transfer system .............................. 2

2. Dry transfer system equipment demonstrated at INEEL ........................................... 5

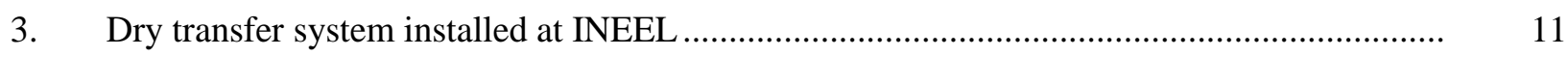

4. Modifications required to mount the TC port cover actuator …....................................... 12

5. Interference between the TC port cover actuator jack and the mezzanine plate.................... 13



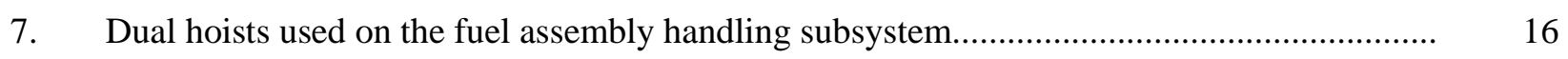

8. Sketch of the fuel assembly transfer tube, crud catcher, and fuel grapple ............................. 17

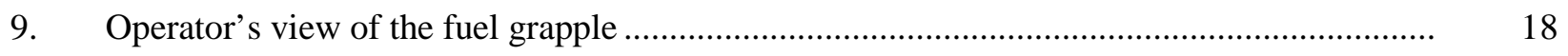

10. Interference between the open crud catcher and the TC port cover rails.............................. 19

11. Kellem cable grips at the top of the fuel grapple ........................................................... 19

12. Fuel Assembly Handling Subsystem grapple stop bracket and cam lever relationship........... 21

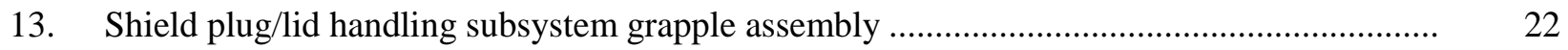

14. Cask interface system in relationship to the top of the cask ............................................... 23 


\section{TABLES}

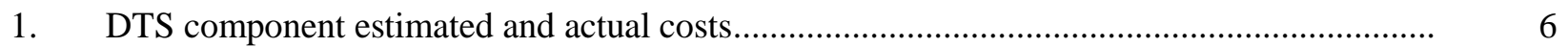

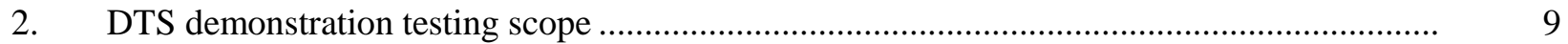

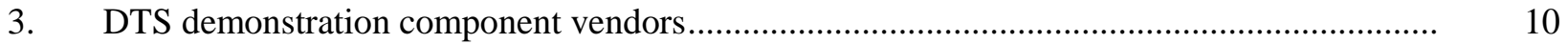




\section{ACRONYMS}

\begin{tabular}{|c|c|}
\hline CCTV & Closed Circuit Television \\
\hline CIS & Cask Interface Subsystem \\
\hline CRT & Cathode Ray Tube \\
\hline DOE & U.S. Department of Energy \\
\hline DOE-ID & U.S. Department of Energy, Idaho Operations Office \\
\hline DOE-HQ & U.S. Department of Energy, Washington, D.C. \\
\hline DOE-RL & U.S. Department of Energy, Richland (Washington) Operations Office \\
\hline DTS & Dry Transfer System \\
\hline EPRI & Electric Power Research Institute \\
\hline FAHS & Fuel Assembly Handling Subsystem \\
\hline FDI & Fluor Daniel, Inc. \\
\hline HVAC & Heating, Ventilation, and Air Conditioning \\
\hline INEEL & Idaho National Engineering and Environmental Laboratory \\
\hline LWR & Light Water Reactor \\
\hline $\mathrm{NRC}$ & U.S. Nuclear Regulatory Commission \\
\hline OCRWM & Office of Civilian Radioactive Waste Management \\
\hline PNNL & Pacific Northwest National Laboratory \\
\hline QA & Quality Assurance \\
\hline RFQ & Request for Quotation \\
\hline SPHS & Shield Plug/Lid Handling Subsystem \\
\hline TAN & Test Area North (at INEEL) \\
\hline $\mathrm{TC}$ & Transfer Confinement \\
\hline $\mathrm{TN}$ & Transnuclear, Inc. \\
\hline TP & Test Plan \\
\hline TSAR & Topical Safety Analysis Report \\
\hline
\end{tabular}




\section{Spent Nuclear Fuel Dry Transfer System Cold Demonstration Project}

\section{INTRODUCTION}

The commercial nuclear reactors that began operation more than two decades ago off-loaded spent fuel into storage pools that were designed for temporary storage with eventual reprocessing of spent fuel. In 1982, the Nuclear Waste Policy Act was passed by the U.S. Congress with the intent that the U.S. Department of Energy (DOE) would accept spent fuel for repository disposal in 1998. Delays in the Federal acceptance of spent fuel have increased the pressure on utilities to provide for additional storage capacity. Initially, reracking spent fuel storage pools accommodated the increased storage. More recently, out-of-reactor dry storage has increased to expand spent fuel storage and permit the decommissioning and decontamination of nuclear reactor sites and their spent fuel storage pools.

The development of a dry transfer system (DTS) is being pursued to increase spent fuel storage options. It provides an interface between large and small casks and between storage-only and transportation casks. It can help alleviate the need for maintaining spent fuel storage pools, thus permitting decommissioning of reactor pools after shutdown. It also allows using large concrete or metal casks for temporary onsite storage of spent fuel irrespective of reactor or fuel handling limitation at a reactor site. By providing a dry method of moving spent fuel between casks, the DTS allows a wider selection of storage and transportation options for the future.

Transnuclear, Inc., (TN) was contracted by the Electric Power Research Institute (EPRI) to design the DTS (EPRI 1989; Pennington et al. 1991) and prepare a Topical Safety Analysis Report (TSAR). The final project report was completed in December 1995 (Dawson et al. 1995) and provided to DOE. The TSAR was provided to DOE in August 1996. DOE transmitted the TSAR to the U.S. Nuclear Regulatory Commission (NRC) in September 1996 and it is currently under review (DOE 1996).

In August 1996, DOE initiated a \$4.5 million project at the Idaho National Engineering and Environmental Laboratory (INEEL) to conduct a cold demonstration of the prototype DTS. INEEL procured major components for the system, installed the hardware, and provided demonstration services. Under contract to INEEL, Fluor Daniel, Inc., (FDI) assisted by preparing procurement specifications and providing procurement services for the DTS components demonstrated. EPRI supported the demonstration effort through test planning and reporting.

Initially, cold and hot demonstrations were considered at the INEEL's Test Area North. Funding limited the demonstration to an enhanced cold demonstration of key pieces of the equipment. The objectives of the DTS demonstration were to (1) verify that the DTS equipment works as intended, (2) determine how well the system meets design requirements, (3) determine the ease associated with recovering from off-normal events, (4) provide loading cycle time and throughput rates, and (5) validate major component costs. The remainder of this report will focus on the scope of the demonstration. It will contain a brief description of the complete DTS (Section 2), costs associated with the demonstrated components (Section 3), testing scope and procedures (Section 4), and demonstration results (Section 5). Conclusions and recommendations are presented in Section 6 and cited references in Section 7. Supporting material can be found in the appendixes. 


\section{DRY TRANSFER SYSTEM DESIGN}

The DTS was designed for the onsite transfer of bare spent fuel assemblies between the top-loading source cask and the receiving cask. The source cask can be a small transfer cask or a larger dry storage cask; small changes to the DTS design allow the system to be adapted to a variety of cask designs. The DTS is designed in accordance with the technical and quality assurance requirements of Part 72 of Title 10 of the Code of Federal Regulations. The following brief description of the DTS design is taken from EPRI's project report (Dawson et al. 1995). Additional details can be obtained from that report. Differences between the EPRI-designed DTS and the demonstrated DTS prototype components are given in Appendix A.

The DTS is a two-level concrete and steel structure with a single-level, weather-resistant, Butler-type building (Figure 1). The concrete and steel structure provides confinement and shielding during fuel transfer operations. The base dimension of the facility is about $12 \times 19 \mathrm{~m}(40 \times 60 \mathrm{ft})$ with a height of approximately $15 \mathrm{~m}(45-50 \mathrm{ft})$. The concrete portions of the structure have walls about $1-\mathrm{m}$ (3-ft) thick. With the exception of the concrete shell, all major components are designed to be transportable. This feature enables the same DTS equipment to be used at different locations. The facility consists of three basic areas; the preparation area, the lower access area, and the transfer confinement area.

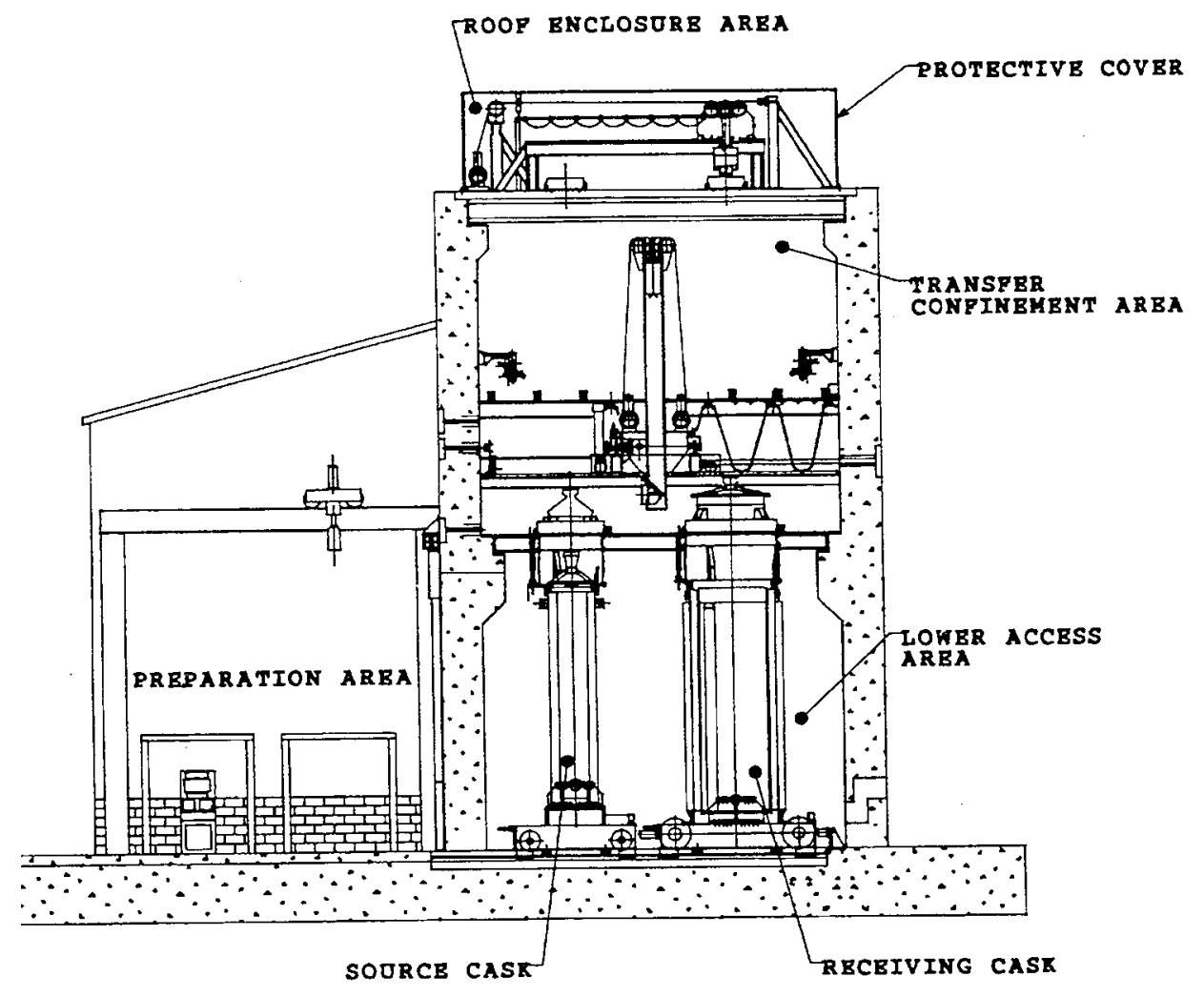

Figure 1. Cross-section of the EPRI conceptual design for a dry transfer system. 


\subsection{DTS Preparation Area}

The preparation area is where the receiving and source casks enter and leave the DTS. It is a weather-resistant Butler-type building at the ground elevation of the transfer facility. It has a roll-up door for cask receipt, a door for personal access, and an 18- to 23-cm (7- to 9-in.) thick steel sliding door that separates it from the lower access area. On entering the preparation area, the casks are prepared for fuel transfer, which includes unbolting of the source cask lids, emplacement of a lifting pintle, and venting of the source cask gas. At the conclusion of fuel transfer, this area is used for cask decontamination and closure activities.

\subsection{DTS Lower Access Area}

The lower access area is adjacent to the preparation area and directly below the transfer confinement area. The lower access area is located within the concrete and steel structure of the DTS. This area provides shielding, confinement, and positioning for the open source and receiving casks. The only entrance is through the 18 - to 23 -cm (7- to 9-in.)-thick sliding steel door. This area is where the casks are positioned prior to fuel transfer operations. After being locked in place in the lower access area, the casks are mated to an opening in the steel floor of the transfer confinement area. The lower access area also houses the bulk of the heating, ventilating, and air-conditioning (HVAC) equipment.

\subsection{DTS Transfer Confinement Area}

In the transfer confinement (TC) area, the fuel assemblies are transferred from one cask to the other. The transfer confinement area is the upper level of the transfer facility and is directly over the lower access area. Like the lower access area, it is located within the concrete and steel structure of the DTS. The transfer confinement area can be entered only through two covered openings in the roof or through two covered openings in the transfer confinement area mezzanine floor. The two roof openings are used by an overhead crane to access the cask shield plugs. The two covered openings in the transfer confinement area mezzanine floor are used for interfacing with casks in the lower access area.

The roof of the transfer confinement area is an 18 -cm $(7$ in.)-thick steel plate that provides shielding to the environment and support for a roof enclosure area and an upper crane. The upper crane is used to lift and lower the receiving cask shield plug and the source cask lid. Two openings in the roof plate directly above the source and receiving casks allow the upper crane access to the main region of the transfer confinement area and to the cask lids. The potential for radioactive contamination is highest in the transfer confinement area. It is maintained at a pressure slightly lower than atmospheric and lower than the preparation and lower access area to maintain airflow from regions of lowest potential contamination to regions of highest potential contamination.

\subsection{DTS General Operating Functions}

The DTS is designed to provide the following operations:

- $\quad$ Move both the receiving and source casks into the preparation area.

- $\quad$ Prepare the receiving and source casks in the preparation area for entry into the lower access area and for interfacing with the transfer confinement area.

- Move and position both the receiving and source casks into the lower access area. 
- $\quad$ Close and lock the sliding steel door that separates the preparation and lower access areas.

- Mate the top of the casks with the transfer confinement area using a cask interfacing system to minimize contamination spread during fuel transfer.

- $\quad$ Remove each cask's shield plug or lid.

- $\quad$ Perform fuel transfer operations.

- $\quad$ Replace each cask's shield plug or lid.

- $\quad$ Disengage the cask interfacing system.

- Unlock and open the sliding steel door between the lower access and preparation areas.

- $\quad$ Remove each cask from the lower access area.

- $\quad$ Complete closure of each cask in the preparation area.

- Decontaminate each cask.

- $\quad$ Remove each cask from the preparation area. 


\section{DTS COSTS}

DTS costs have been estimated at several points in the development of the system. TN estimated the cost of the total system as part of their design effort (Dawson et al. 1995). Later, FDI estimated the cost of several major components as part of their procurement effort. The system estimated by FDI is shown in Figure 2. A compilation of estimated and actual costs is presented in Table 1. In comparing the costs, it should be noted that the DTS demonstration test equipment differs to some extent from the commercial DTS conceptualized in the EPRI system. These differences were driven by conditions specific to the demonstration test and the location for the test. Some of the procured equipment was modified to provide cost savings. Finally, actual costs of these major components were collected during the procurement. The procurement requested fixed price cost proposals from qualified vendors. For the fuel assembly handling subsystem, four quotes were received ranging from $\$ 375,000$ to $\$ 1,005,000$. FDI had used $\$ 440,000$ in its early estimated of equipment costs. Much of the disparity between proposals was due to a lack of clear delineation of what was considered hardware and what was considered control system.

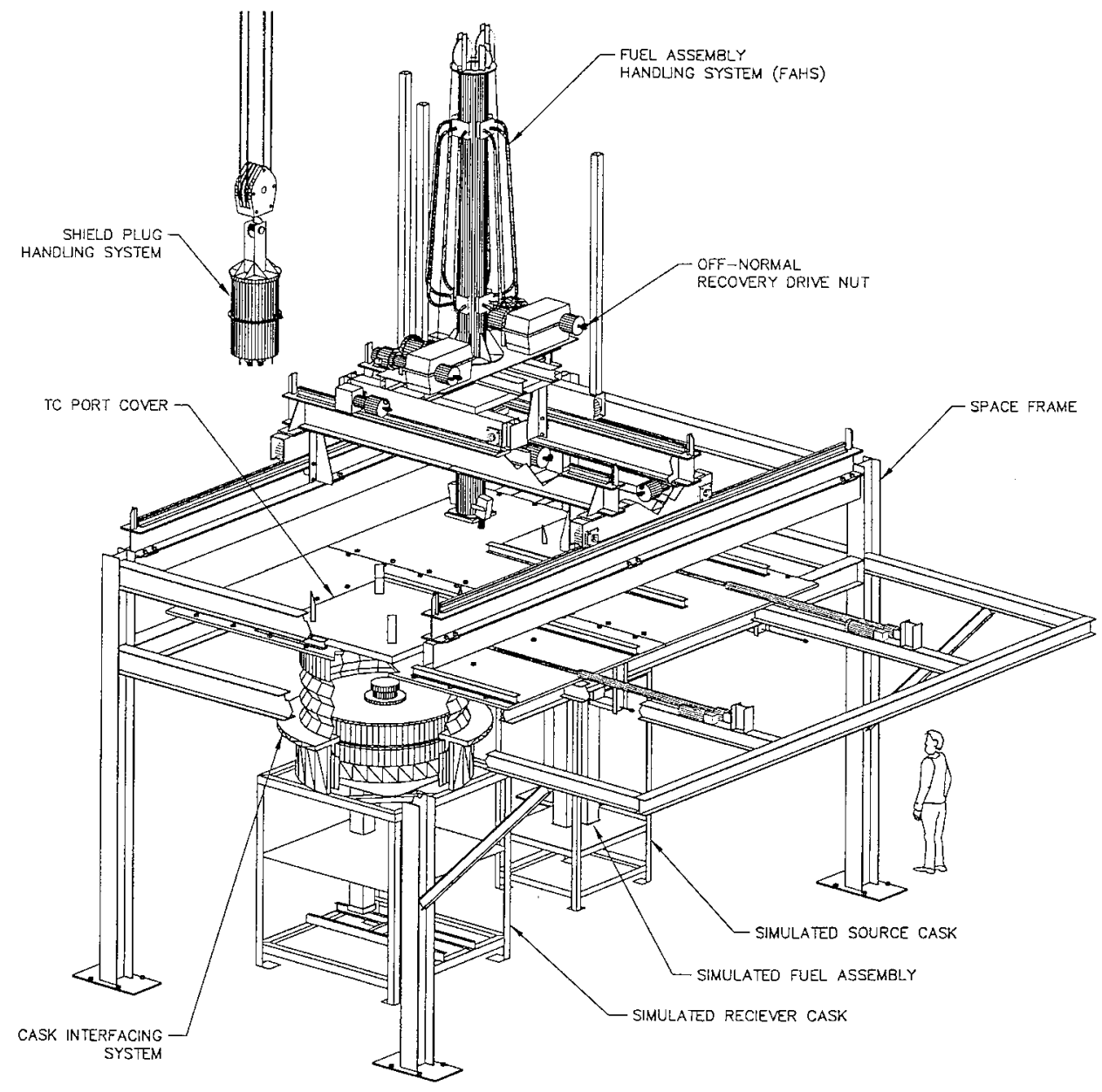

Figure 2. Dry transfer system equipment demonstrated at INEEL. 
Table 1. DTS component estimated and actual costs.

\begin{tabular}{|c|c|c|c|c|}
\hline Component, Item Description & $\begin{array}{l}\text { TN Estimated } \\
\text { Cost }\end{array}$ & $\begin{array}{c}\text { FDI } \\
\text { Estimated } \\
\text { Cost } \\
(7 / 96)\end{array}$ & $\begin{array}{c}\text { FDI } \\
\text { Estimated } \\
\text { Cost } \\
(12 / 96)\end{array}$ & $\begin{array}{c}\text { Purchase Cost } \\
(4 / 97)\end{array}$ \\
\hline Lower access area and transfer confinement area & $\$ 1,689,000$ & & & \\
\hline Preparation area & $\$ 145,000$ & & & \\
\hline Cask transfer subsystem & $\$ 510,000$ & & & \\
\hline Fuel assembly handling subsystem & $\$ 540,000$ & $\$ 440,000$ & $\$ 550,000$ & $\$ 633,800$ \\
\hline Upper crane & $\$ 500,000$ & & & \\
\hline Shield plug/lid handling subsystem ${ }^{\mathrm{a}}$ & & $\$ 27,000$ & $\$ 111,875$ & $\$ 200,512$ \\
\hline TC port covers ${ }^{\mathrm{b}}$ & $\$ 100,000$ & $\$ 46,000$ & & \\
\hline TC cask interfacing subsystem ${ }^{\mathrm{b}}$ & $\$ 700,000$ & $\$ 218,000$ & $\$ 321,875$ & $\$ 322,014$ \\
\hline Mezzanine plate $^{\mathrm{b}}$ & & $\$ 70,000$ & & \\
\hline Closed-circuit television subsystem $^{\mathrm{c}}$ & $\$ 241,000$ & $\$ 15,000$ & & $\$ 130,930$ \\
\hline Control subsystem & $\$ 90,000$ & $\$ 123,000$ & $\$ 153,750$ & $\$ 78,057$ \\
\hline General lighting subsystem & $\$ 7,000$ & & & \\
\hline Radiation monitoring subsystem & $\$ 85,000$ & & & \\
\hline Power subsystem & $\$ 200,000$ & & & \\
\hline HVAC subsystem & $\$ 305,000$ & & & \\
\hline Packaging subsystem & $\$ 39,000$ & & & \\
\hline TN design scope subtotal & $\$ 5,151,000$ & & & \\
\hline MPC weld equipment & $\$ 300,000$ & & & \\
\hline Leak test, vacuum pump, valves, etc. & $\$ 30,000$ & & & \\
\hline Miscellaneous hardware & $\$ 50,000$ & & & \\
\hline Mezzanine support frame $^{d}$ & & $\$ 26,000$ & $\$ 122,000$ & $\$ 65,000$ \\
\hline Other equipment required subtotal & $\$ 380,000$ & & & \\
\hline Site-specific structural design & $\$ 100,000$ & & & \\
\hline Site preparation & $\$ 250,000$ & & & \\
\hline Transportation of fabricated equipment to site & $\$ 50,000$ & & & \\
\hline Installation crane rental ( 2 weeks at $\$ 5 \mathrm{~K} /$ week) & $\$ 10,000$ & & & \\
\hline Project engineering costs & $\$ 330,000$ & & & \\
\hline Procurement administrative costs & $\$ 85,000$ & $\$ 275,000$ & & \\
\hline A-E bid and award support & & $\$ 25,000$ & & \\
\hline Site-specific subtotal & $\$ 825,000$ & & & \\
\hline Fees to support the NRC staff review & $\$ 200,000$ & & & \\
\hline Site-specific licensing support & $\$ 100,000$ & & & \\
\hline NRC review specific subtotal & $\$ 300,000$ & & & \\
\hline Contingency & $20 \%$ & $\$ 330,750$ & $25 \%$ & \\
\hline Total & $\$ 6,656,000$ & $\$ 1,595,750$ & $\$ 1,275,000$ & $\$ 1,430,313$ \\
\hline \multicolumn{5}{|c|}{$\begin{array}{l}\text { a. EPRI estimate includes costs for an upper crane system and upper mezzanine area with shield doors. These items were not included in the FDI } \\
\text { estimate. The DTS demonstration test used the existing overhead building crane. }\end{array}$} \\
\hline \multicolumn{5}{|c|}{ b. The DTS demonstration test included only those mezzanine plates necessary to support the cask interfacing systems. } \\
\hline \multicolumn{3}{|c|}{ c. The DTS demonstration test used only those cameras located in the transfer containment area. } & & \\
\hline
\end{tabular}




\subsection{Procurement Strategy}

The components that compose the DTS were divided into six subsystems, each of which could be specified in a separate request for quotation (RFQ) or could be bundled into RFQs that contain multiple subsystems. A schematic of the demonstration system is shown in Figure 2. The subsystems are as follows:

1. Fuel assembly handling subsystem (FAHS)

2. Shield plug/lid handling subsystem (SPHS)

3. Cask interface subsystem (CIS) (includes the mezzanine)

4. Demonstration control subsystem

5. Support frame.

\section{Closed Circuit Television Subsystem (CCTV) (shown in Figure 3)}

FDI was given responsibility for procuring subsystems 1 through 4 . The INEEL was to provide subsystems 5 and 6 . Vendors were pre-qualified for the work proposed prior to the issuance of an RFQ. RFQs for each subsystem were sent to vendors deemed to have capabilities specific to the subsystem. In some instances, a particular vendor received multiple RFQs. Due to the small number of responses received for the CIS, the RFQ for the support frame was included with the package and a new RFQ sought. This strategy resulted in a more reasonable cost proposal being received for both subsystems 3 and 5.

Following a review of the four initial scoping vendor proposals submitted for the FAHS, FDI made plans to seek separate proposals for the hardware and the control systems. Vendors were asked to submit three proposals: one for the hardware only, one for the control system only, and one for a complete system, hardware and controls. From these, FDI selected the lowest-cost proposal for the hardware only and the lowest-cost proposal for the control system only.

Vendors began working on their respective systems based on the procurement specifications and drawings prepared by FDI. It was not until late in the design that each vendor was given copies of the others' actual design drawings to examine and to establish communication paths. It became clear to the vendors that key communication items were assumed supplied by the other vendor and were missing from each of the designs. A meeting was called with the FAHS vendor, the control system vendor, and FDI to work out the problems. The control system vendor then submitted a revised bid.

There was also some regret expressed by both the control system and the FAHS vendors that they were not involved in each other's design efforts at an earlier stage. Some duplication of components used for control could have been avoided as well as a consolidation of space in electrical cabinets. It would have been very cost effective to have had the control system vendor on the design review team for the hardware manufacturers and to have allowed him to have a say in specifying components used in the control of the hardware.

In addition to the six subsystems mentioned above, the INEEL provided two simulated casks, a simulated fuel assembly, and an Off-Normal recover tool for the demonstration. The simulated casks represented a Transnuclear TN-8L cask and a NUHOMS ${ }^{\circledR}$ MP-187 cask. The simulated fuel assembly represented a Westinghouse $15 \times 15$ array fuel assembly. 


\subsection{Quality Assurance Requirements-Impacts on Costs}

The design requirements originally called for the equipment to be fabricated to NQA-1 requirements. At the time the equipment procurement specifications were being readied, the DOE/RW-0333P, Quality Assurance Requirements and Description, quality assurance requirements were imposed on the design, procurement, fabrication, inspection and testing activities. This resulted in additional indoctrination, training and record keeping for those involved in the design and manufacture of the DTS.

A key cost contributor to the Project was that the supplemental and some basic requirements of NQA-1, "Quality Assurance Requirements for Nuclear Facility Application" had not been fully proceduralized and implemented by FDI. The combination of bringing QA programs into compliance with NQA-1 and amplifying NQA-1 requirements to meet DOE/RW-0333P was a major contributor to cost. Most FDI project participants were not familiar with the differences between NQA-1 and DOE/RW-0333P, further adding to the implementation cost. INEEL quality assurance personnel spent a considerable amount of time helping FDI implement these requirements. Items designated Important to Safety (ITS) were procured under NQA-1 and other national consensus standards such as ASME NOG-1 for the fuel handling crane. These requirements were amplified to meet DOE/RW-0333P commensurate with the procurement activity. This approach, to amplify requirements in lieu of invoking DOE/RW0333P specific on DTS equipment fabricators, was taken to reduce procurement costs. The results were considered positive in reducing cost.

Some $\$ 175 \mathrm{~K}$ in added design and procurement costs and $\$ 200 \mathrm{~K}$ in equipment costs were attributed directly to the change in quality assurance requirements imposed on FDI. For example, the original minispecification for the FAHS, that was not fully developed, called for an NQA-1 quality assurance program and indicated four paper deliverables. This mini-specification was used by FDI to qualify potential bidders. The final specification, fully developed with the NQA-1 requirements and the requirements of DOE/RW-0333P, required over 50 paper deliverables. The specifications for the FAHS and the SPHS were affected most by the amplifications since they contained items Important to Safety. 


\section{TEST PLAN AND DEMONSTRATION PROCEDURES}

Under EPRI sponsorship, Pacific Northwest National Laboratory (PNNL) prepared a test plan to guide demonstration activities. The test plan was reviewed by the Technical Management Committee for the demonstration and was used by INEEL as a basis for preparing test procedures (Gili 1998). It is included in this document as Appendix B.

\subsection{Testing Scope}

The demonstration included all hardware, related control systems, and interlocks for the shield plug/lid handling subsystem, the fuel assembly handling subsystem, the cask interfacing subsystem, and the close circuit television and lighting subsystem. The demonstration was performed in the Test Area North (TAN) Warm Shop at INEEL using a space frame to support the test components. Testing was limited to a cold demonstration of the fuel and cask interface systems attached to the mezzanine plate between the lower access area and the transfer confinement area of the DTS. The scope of the cold demonstration included functional testing of equipment and a complete series of DTS operations from source cask receipt/opening through fuel transfer to receiving cask closing. The tests included both normal operations and recovery from off-normal events. Because of the Warm Shop's height restrictions, shortened cask and fuel mockups were used. The tests used a three-quarter-length dummy light water reactor fuel assembly that had the same weight as a full-length assembly.

The demonstration did not include the following subsystems: receiving and source cask transfer, HVAC, radiation monitoring, receiving cask lid handling, decontamination, cask transport and lifting, lighting, cask vacuum/inerting/leak-test, canister welding, and DTS power. No demonstration was made or simulated for the interlocks associated with these excluded subsystems. For the demonstration, an existing overhead crane was substituted for the receiving cask shield plug and source cask lid handling subsystem with its dedicated upper crane subsystem, protective cover, and upper shield port covers. The overlid grapple portion of the shield plug/lid handling subsystem was modified and used to interface with the Warm Shop crane. Demonstration components were mounted on a space frame rather than using a prototypic DTS concrete support structure. The cask trolleys, shield door, and associated locks and interlocks were not demonstrated. Table 2 shows which components were demonstrated and which were excluded from the demonstration.

\subsection{Test Procedures}

INEEL and FDI developed test procedures. They addressed test objectives and scope and provided for initial acceptance testing at the vendors' fabrication facilities before shipment, integration of various systems at INEEL, confirmation of alarms and interlocks, and safety requirements at the test site.

Table 2. DTS demonstration testing scope.

$\begin{array}{cl}\text { Subsystems Demonstrated } & \text { Subsystems Not Demonstrated } \\ \text { Shield Plug/Lid Handling } & \text { Receiving and Source Cask Transfer } \\ \text { Fuel Assembly Handling } & \text { Receiving Cask Lid Handling } \\ \text { Cask Interfacing } & \text { Cask Transport and Lifting } \\ \text { Closed Circuit Television and Lighting } & \text { Vacuum/Inerting/Leak Test } \\ \text { System Interlocks (partial) } & \text { Canister Welding } \\ \text { System Substitutions } & \text { Decontamination } \\ \text { Overhead Crane } & \text { HVAC } \\ \text { Space Frame } & \text { Radiation Monitoring } \\ \text { Off-Normal Recover } & \text { DTS Power }\end{array}$




\section{DEMONSTRATION RESULTS}

The components of the DTS demonstrated at the INEEL's Test Area North are divided into five subsystems. Four of these subsystems were procured for the INEEL by FDI. The subsystems and their respective suppliers are listed in Table 3. Each subsystem underwent a performance test at the vendor's facility before being shipped to the INEEL for installation in the integrated system. The system installed at the INEEL is shown in Figure 3.

The demonstration test was designed to deliberately challenge the system and determine whether any specific system operation could adversely impact or jeopardize the operation or safety of any other function or system. All known interlocks were challenged. Following system modifications, additional testing was performed to validate the modifications. In general, all the equipment worked exceptionally well. It ran smoothly and functioned as designed. As in all new systems, a few "bugs" had to be corrected. The following sections detail some of the initial "bugs" in the system along with other observations.

\subsection{Acceptance Testing}

The original plan was to have all equipment designed, fabricated, assembled at the FAHS vendor's facility, and pre-tested to ensure everything worked together. Because of delays in obtaining equipment, this did not happen. Instead, only the control system and the FAHS were assembled together and pre-tested. The control system, the cask interfacing subsystem, and the shield plug/lid handling subsystem were not integrated until final assembly at the INEEL. All initial acceptance tests for the equipment were performed at the vendor's facility using simulated control system inputs. Final acceptance testing was performed at the INEEL after the systems were integrated.

The proof tests and calibration of the load cells associated with the shield plug/lid handling subsystem were a one-time test performed at 300\% of design load. The manufacturer performed this test prior to shipping the equipment to INEEL. FDI and INEEL representatives witnessed these proof tests.

The proof tests were not repeated at the INEEL. The assembled FAHS was operationally tested at $125 \%$ of its rated capacity to comply with INEEL requirements for periodic operational tests of lifting equipment.

Table 3. DTS demonstration component vendors.

\begin{tabular}{ll}
\hline \multicolumn{1}{c}{ Subsystem Description } & \multicolumn{1}{c}{ Vendor } \\
\hline Demonstration control subsystem & $\begin{array}{l}\text { Vision Engineering } \\
\text { Cypress, CA }\end{array}$ \\
Fuel assembly handling subsystem & NES, Inc. \\
& Danbury, CT \\
Shield plug/lid handling subsystem & Alpha Engineering \\
& Pocatello, ID \\
Cask interface equipment, mezzanine, and support frame & American Fab \\
& Idaho Falls, ID \\
Closed-circuit television and lighting subsystem & INEEL \\
\hline
\end{tabular}




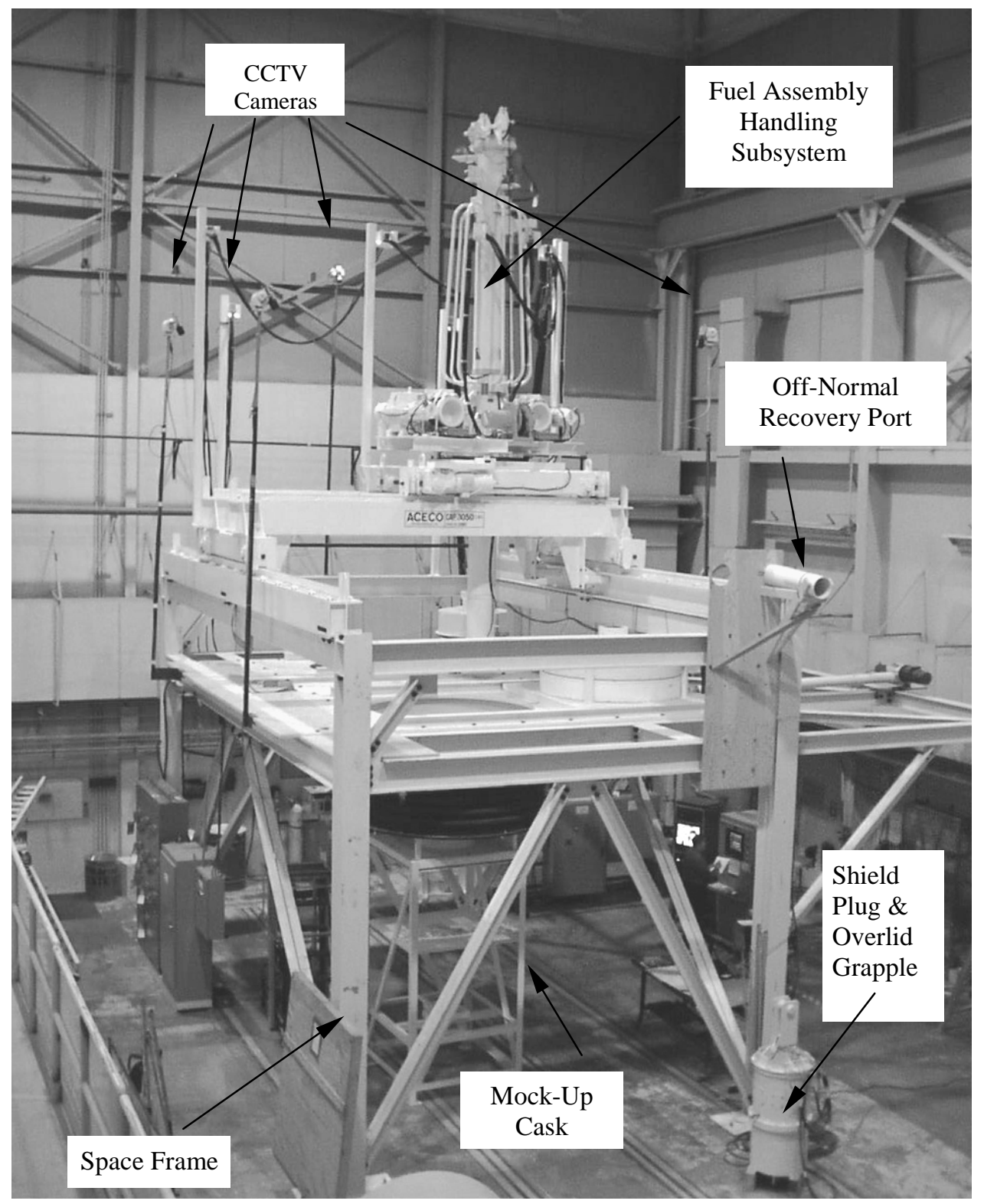

Figure 3. Dry transfer system installed at INEEL.

\subsection{Equipment Assembly and Installation}

Installation and assembly of the equipment at the INEEL was hampered by several factors. First of all, there was no requirement for the vendor to supply a field assembly plan, nor to provide field support during assembly. The INEEL had expected the equipment to be pre-assembled and tested as a final assembly prior to delivery. However, because the total equipment integration did not take place as originally planned and because of schedule constraints, the decision was made to assemble the equipment at the INEEL as it arrived, using existing drawings. In some cases, these drawings were not as-built, so integrating the equipment took more time than anticipated.

It was impossible for the INEEL to determine the number and size of cabling required to integrate the various systems from the drawings at hand. "Wiring by others" shown on drawings was used to show 
wiring to be supplied by both other vendors and the INEEL. Frequent contact with equipment vendors was necessary to determine the correct wiring schemes. There were instances where discussions between vendors had resulted in the wiring schematics being changed, and these changes were not shown on the drawings being used by the INEEL for installation of the equipment. As a result the field integration was performed with many separate wire cables, instead of a few multi-conductor cables, installed between control panels. This resulted in inefficiencies in installation and equipment checkout.

As the subsystems integration progressed at the INEEL and discussions took place with vendors, it was determined there was some redundancy in systems that had to be removed. All the vendors commented that many components could have been eliminated and systems compacted by better and earlier communication between the control system vendor and the hardware vendors during the design phase.

There were several fit-up challenges that had to be addressed during installation of the equipment. The end bracket for the receiver cask TC port cover actuator required modification and an extension plate attached to the space frame to facilitate mounting of the motor end of the receiver cask TC port cover actuator (see Figure 4). Interference between the outer housing of the Receiver Cask TC port cover actuator and the mezzanine plate and between the end plate of the actuator and the bolt heads securing the support beam precluded installation of the actuator in a level position. It appears that the actuator had a larger diameter than specified by the design, which caused the interference scratch shown in Figure 5. It

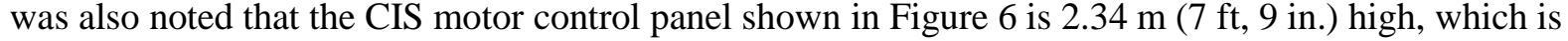
probably too large for a standard trailer control room.

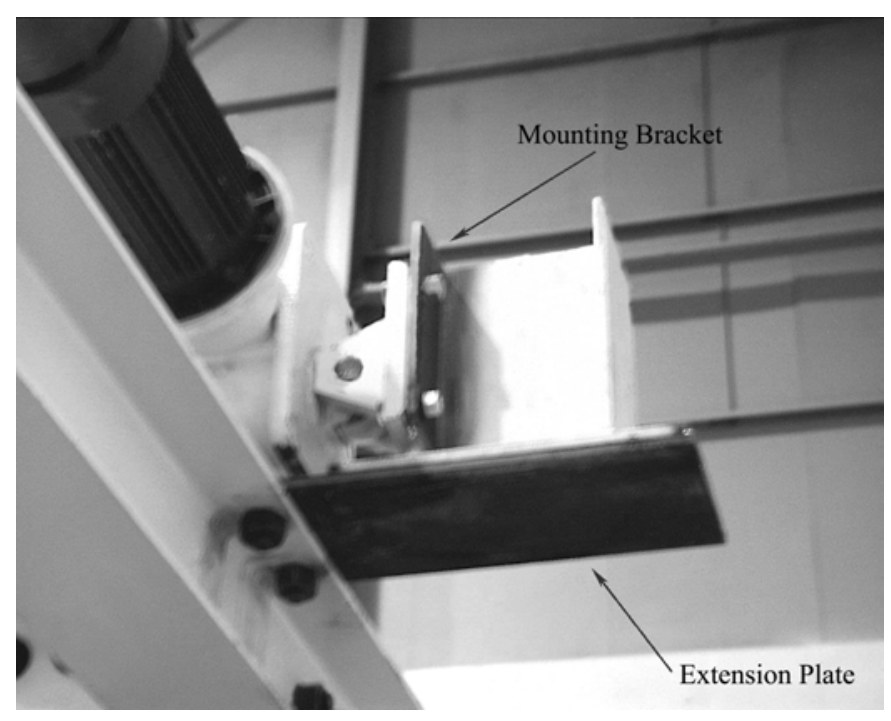

Figure 4. Modifications required to mount the TC port cover actuator. 


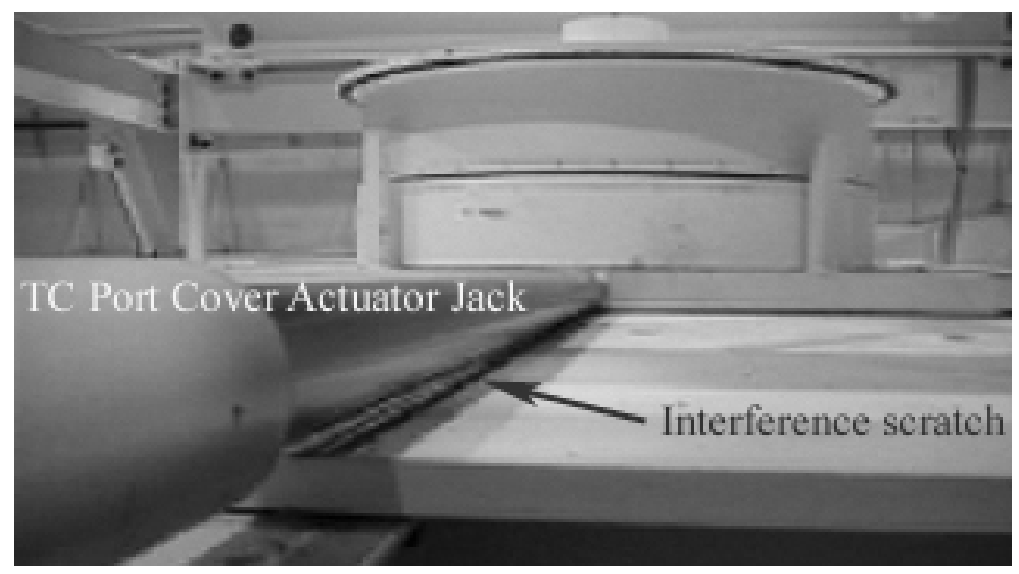

Figure 5. Interference between the TC port cover actuator jack and the mezzanine plate.

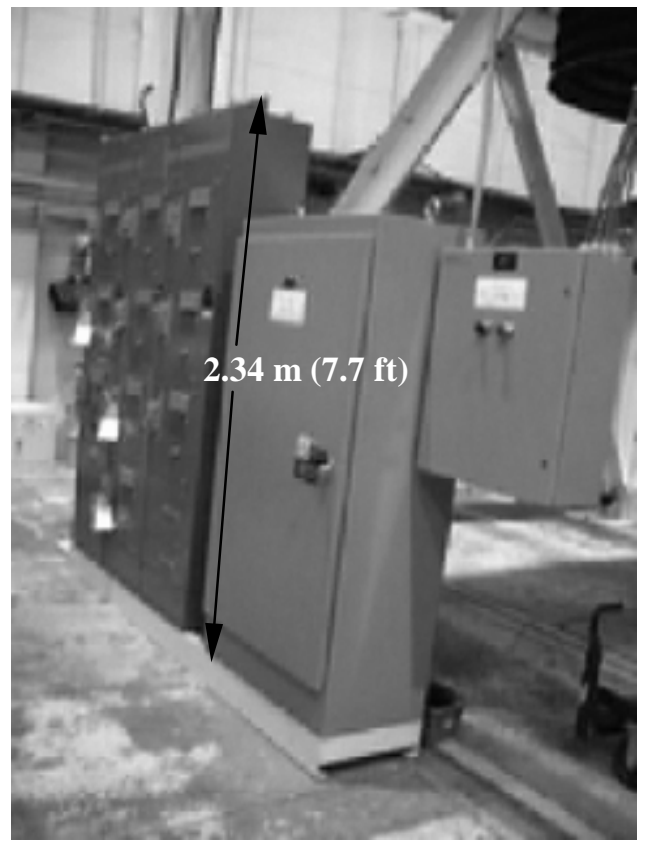

Figure 6. Cask interface system motor control panel.

\subsection{Control System}

More and earlier interaction between the control system vendor and the hardware vendor would have helped to eliminate redundancies in control functions. Greater efficiency could have been achieved if the control system vendor had been (1) given responsibility for assembling the control panels or (2) included in the review cycle for the hardware vendor's panels, and allowed to specify and/or supply some of the components to be placed in the panels. As supplied, there was a need to bypass some of the relays installed by the hardware vendor in his control panels so the control system would function properly. 
The control system vendor's contract specified two weeks for subsystem integration and troubleshooting. This time was used during the integration of the control system and the FAHS. There was no time left for integration of the remaining subsystems. Consequently, additional costs were incured in bringing the control system vendor to the INEEL for assistance in integrating the CIS and SPHS with the rest of the systems. Given that the Project was a research and development type project, the control system vendor's contract should have had a clause for retaining troubleshooting services during system startup and throughout the demonstration test. Experience derived from the demonstration resulted in the correction and modification of several control functions, including changes required to debug the system and enhance its performance.

Several control functions, such as raising and lowering the CIS bellows, required constant pressure on the control button to maintain movement. At the recommendation of the INEEL operation technicians, software changes were made to allow the action to continue without constant button pressure, and a STOP button was added to allow partial raising and lowering of the bellows. Originally, the FAHS allowed movement of a fuel assembly only in the SLOW mode. This required the operator to hold down the control button for the entire 20 minute retrieval operation. This operation was modified to allow high-speed movement of the fuel assembly. The fuel movement procedure should require slow movement of the assembly until the FAHS grapple has cleared the opening in the transfer tube and the fuel assembly has cleared the top of the canister.

The original control system was supplied with a Wonderware runtime license. This allowed the software program to run but prohibited modifications being made. The engineer/operator was even prohibited from making simple changes such as setting the North, South, East, and West movement designations to correspond with site-specific equipment layout. In addition, some routine maintenance requires periodic changes to the software such as changing fuel assembly grapple load limits to allow the system to be load tested. Diagnostics were also limited. In the original software program, there were no provisions for the operator to view or modify the raw data input from the sensors or to modify control functions. The demonstration highlighted the need to have the capability to edit the control software. Additional data that could be used in troubleshooting the system operation was also required.

A Wonderware development package was purchased to allow editing of the man/machine interface screens. Likewise, an Allen-Bradley Ladder Logic software license was obtained that provides additional editing capabilities for operation and maintenance of the equipment. Purchase of these development packages allows the user to legally edit and maintain the software after the software contractor's involvement with the project ends.

Software changes during the course of the demonstration fixed inconsistencies in display colors used to indicate progress or completion of a task and nomenclature used on the computer control screens. Both hardware and software changes were required to get the Emergency Stop buttons to function properly. In the as-received condition, they would not latch in the engaged position when pushed. To work, they had to be physically engaged and held. They could also be locked in the disengaged position using a key.

Two sets of engineering screens were added to the control system software. Two I/O status screens allow the operator to view the status of the various switches. The two engineering screens allow the operator to view the current settings for limits and allow the limits to be changed. These changes are only valid while the system remains powered. For these changes to become permanent, they must be burned into the Eprom chip. These engineering change screens are protected by passwords.

The vendor provided no specific program logic controller diagnostics for the control system. It would be helpful to the operator if tables of interlocks and alarms were prepared and included in the 
Operations and Maintenance Manual. The tables should be arranged so the operator can use them to troubleshoot the system when an alarm is received. The current alarm messages on the screen are sometimes too vague to provide useful troubleshooting information.

In the EPRI system (Dawson et al. 1995), alarms are designated as "critical" and "non-critical." The critical alarms are to stop current operation, and the non-critical alarms are to warn of potential problems. However, all alarms in the DTS stop the system until they are cleared. The control system has an acknowledgement function, but acknowledging the alarm has no effect other than to change the color of the alarm text on the Cathode Ray Tube (CRT) screen.

The following are some suggested additional software changes that could be made to provide ease in operating the system:

1. Allowing retention of setpoints when the system is shut down and the ability to reload this group of setpoints during system startup. Currently, the system loads a default set of setpoints on startup. It would be helpful to allow storage of multiple sets of set points in memory that could be recalled by the operator. There needs to be some indication of when set points have been accepted so an operator can easily verify when intended changes are correctly entered into the computer.

2. Providing overrides on interlocks that must be disabled to perform the standard load test on the crane. Currently, the ladder logic source code must be edited to disable the interlocks and then restored after the test is completed.

3. Combining the source and receiving cask screens for the TC port cover and cask interfacing system would simplify operations by allowing both operations to be completed without changing screens. It would also be helpful to allow both source and receiving TC port cover operations to occur in parallel rather than in series. There is no possibility of interaction between systems during parallel operation. Parallel operation would save some time.

It should also be noted that the system usually receives six errors on every startup (bridge, trolley, and secondary hoist, over and under travel alarms) because of the sequence of starting the control system and then powering the individual hardware vendor's control panels. Efforts to remove these alarms have not been successful. They are expected and are dealt with in the startup procedures.

The startup procedure for the DTS is to first power up the computer control system. This system starts automatically upon receiving 120 volt power. All 480 volt power breakers except for the Fuel Assembly Handling System Secondary Control panel are then turned on. After the load cell readout on the Fuel Assembly Handling System Primary Control panel have initialized, the Fuel Assembly Handling System Secondary Control panel is turned on. At this point the operator must go into the main computer control system and clear the six alarms mentioned previously.

This startup sequence is an example of where two vendors are doing the same sensor checks. A major redesign effort would be required to consolidate these two checks into one and eliminate the error messages.

Spurious alarms are also encountered. They appear to be caused by vibration or electrical impulses from activities such as the activation and/or sudden stopping of motors or actuators. There may be coupling between power and signal cabling caused by cable routing. The current system has not adequately segregated power and control signals cable routing. Sensor sensitivity may also contribute to the spurious alarms. Future systems should consider cable routing schemes that include segregated power 
and control signals, a reduction in excess and loose cable, and better cable supports. Care should be taken in adjusting the sensitivity of sensors.

During system operation, some bits of the Allen Bradley program would suddenly disappear. This would happen without any changes being made to the program. It would become necessary to look at the ladder logic and add the bits back into the program. At times, when the system was fired up at the start of a shift, it would run rather sluggish. The bridge would seem to not run at full speed, etc. It was necessary at this point to power down and then restart the complete system. For some reason, the program would not load right. To alleviate these types of problems, the system really should be run in a simulated production mode of just moving a simulated fuel assembly back and forth between the two casks for a period time to identify and correct some of these lingering software problems.

\subsection{Fuel Assembly Handling Subsystem}

The FAHS used in the demonstration was designed with a dual-motor hoist to provide increased reliability (see Figure 7). Two complete hoist systems, each capable of handling the load independently, are active during normal operations. The two frequency drives analyze the data from the torque sensors on each motor and adjust each motor's speed to maintain equal cable tension. A temporary wiring modification is required to lower a load using a single hoist. Signals from load cells attached to the two cables are used to determine the FAHS crane load. Currently, the highest reading is sent to the computer control system, and the other is ignored. As the load shifts between the cables due to swinging, starts, stops, and load sharing, the calculated weight shifts constantly. This may contribute to many of the spurious signals received by the control system. Similar fluctuations occur in the SPHS grapple. Future designs or design modifications should consider these things.

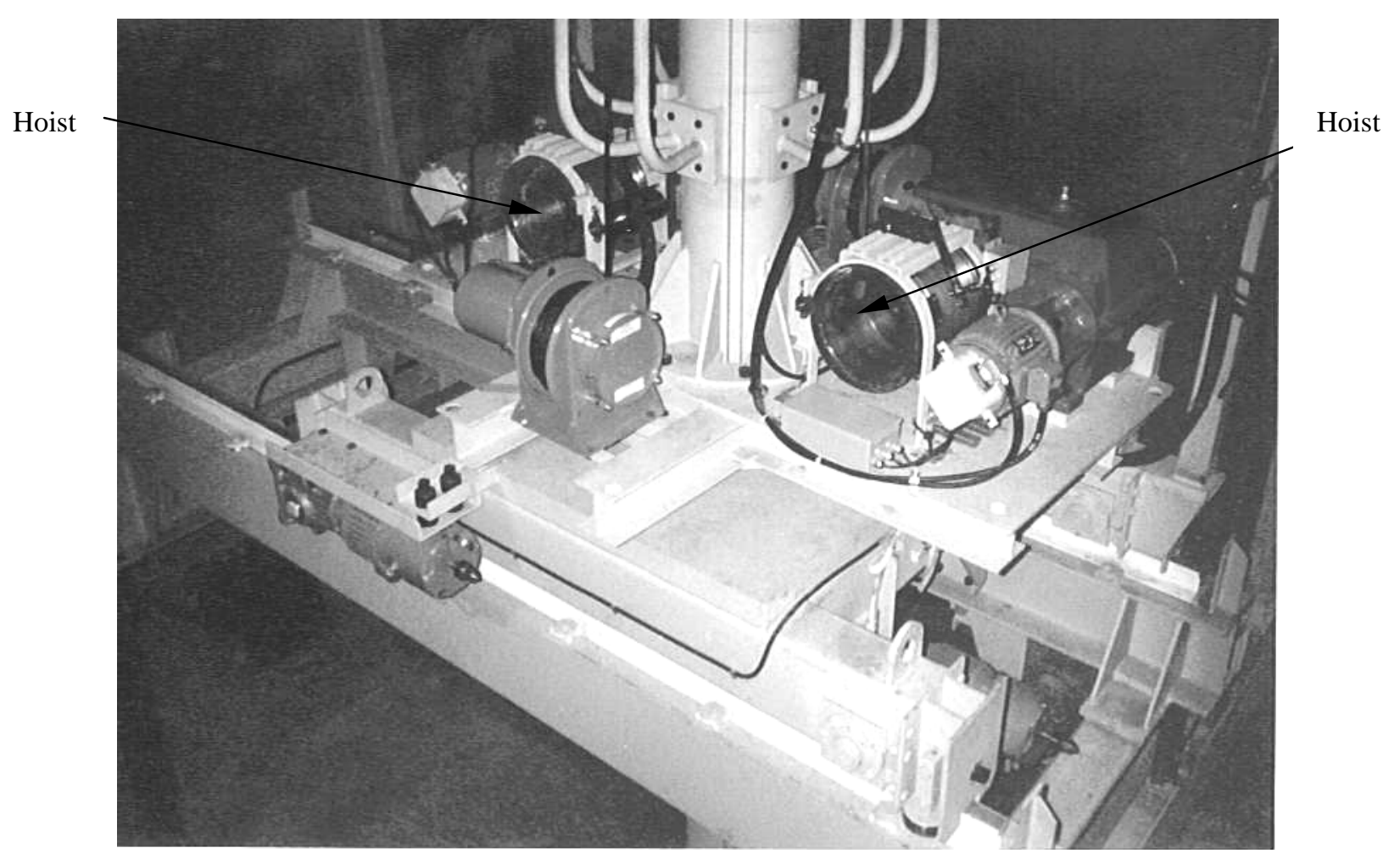

Figure 7. Dual hoists used on the fuel assembly handling subsystem. 
Consideration should be given to providing a cover for the fuel grapple actuating mechanism to prevent catching a cable between the grapple and the transfer tube. Figure 8 shows the fuel grapple in relation to the cable sheaves that carry the fuel assembly and grapple loads during fuel transfer.

To engage the grapple with the fuel assembly or to disconnect the grapple from the fuel assembly, the grapple must be resting on the top of the fuel assembly with slack in the cables, as shown in Figure 9. Figure 9 shows the cables while working in the Receiver Cask. The operator does not have this good of a view of the cables while working in the Source Cask. Observing the cables is an erratic indication of whether or not the grapple fingers will operate. The operator needs to control the cables so they do not jump out of the sheave or become caught between the transfer tube and the grapple. Either condition can cause damage to the grapple. The secondary hoist cable, the cable running through the upper sheave on the load block assembly, did come out of the sheave on two occasions and become wedged around the sheave shaft. One of these occasions happened while the system was being tested using only one hoist.

The grapple should be redesigned to release the fuel at some minimum load on the cables. Release of the fuel from the grapple should not be contingent upon obtaining slack in the cables. Slack in the cable leads to additional problems such as the cable being caught between the grapple and the fuel tube or the cable coming out of a sheave. A backup means of releasing fuel from the grapple should be provided. It was also noted that the grapple twists under load.

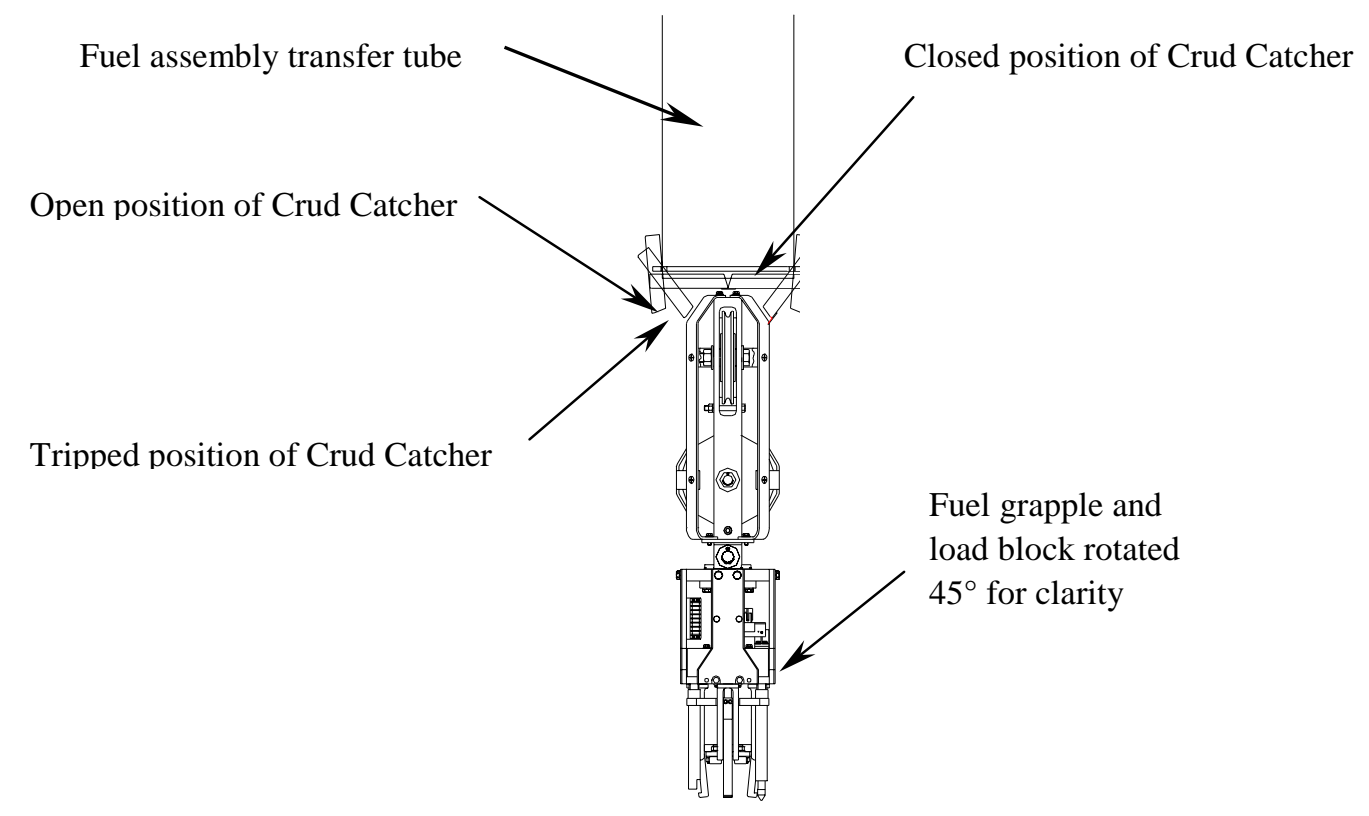

Figure 8. Sketch of the fuel assembly transfer tube, crud catcher, and fuel grapple. 

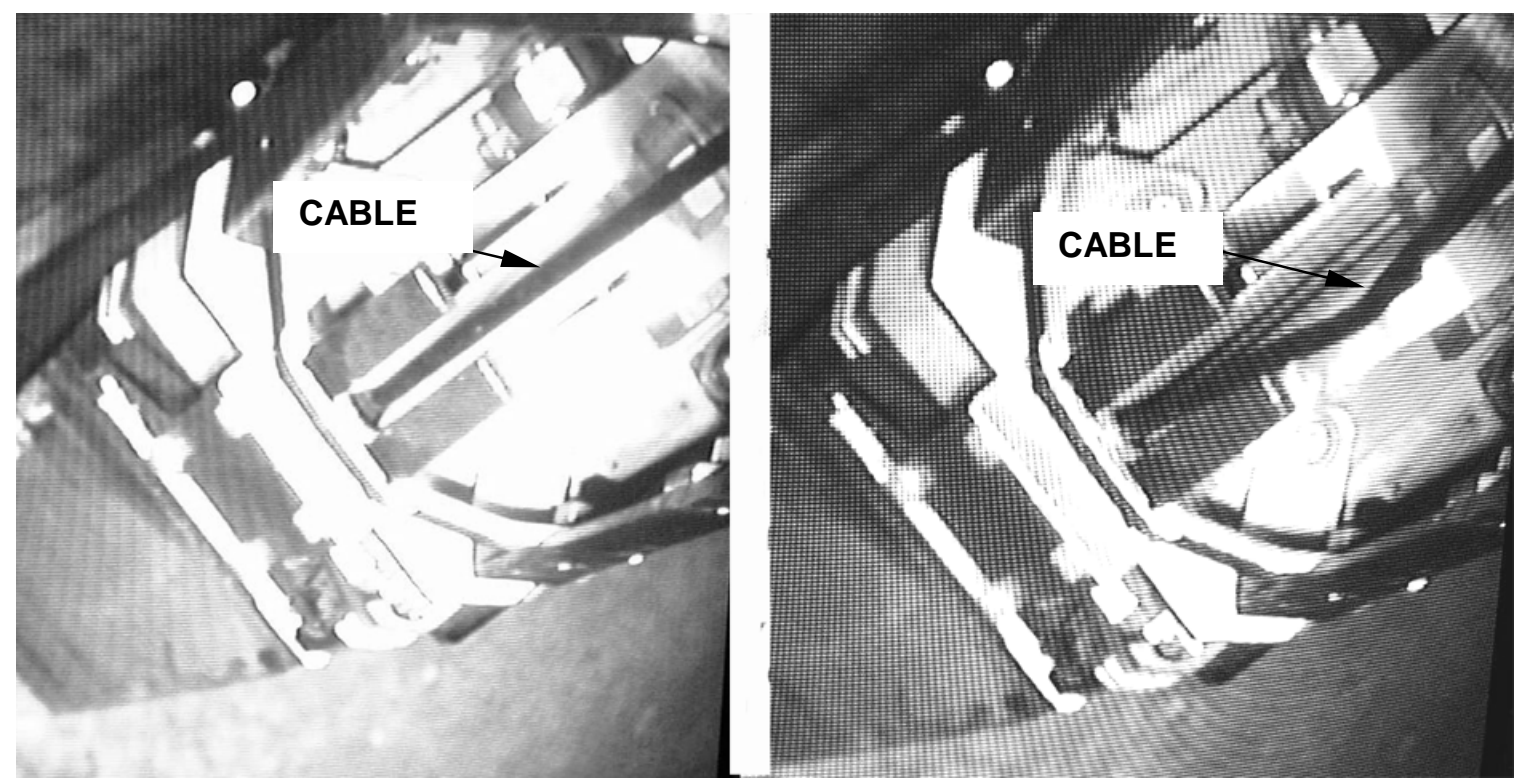

Figure 9. Operator's view of the fuel grapple. The figure on the left shows the condition of the cable when the grapple is loaded and lifting the fuel assembly. The figure on the right shows the slack in the cable required prior to actuation of the grapple, i.e., prior to engaging a fuel assembly.

Several potential problems were observed in the operation of the crud catcher. If the crud catcher jams or fails and cannot be opened, a fuel assembly can be lowered through the crud catcher by tripping the emergency cable release, a breakaway pin-socket assembly. Currently, when the emergency cable release is tripped, the crud catcher does not fail in a completely open position. In a partially open position, it would allow the fuel assembly to be lowered into a cask but would not allow the grapple to be retracted into the transfer tube (Figure 8). This would prevent the FAHS being moved to the "park" position and the shield plug being placed into the cask. Modifying the crud catcher design so it would fail in the fully open position would alleviate these potential problems.

The crud catcher position sensor is presently located above the emergency cable release. Thus, when the emergency cable release is activated, the position sensor continues to signal a closed crud catcher and movement of the bridge and/or trolley is permissible. This sensor needs to be relocated so it can accurately monitor the crud catcher position after the crud catcher emergency cable release is activated.

In the open position, the crud catcher extends low enough to contact the TC port cover rails. The interference between the bottom of an open crud catcher and the top of the TC port cover rail is shown in Figure 10. Movement of the fuel assembly transfer system across the rails with an open crud catcher causes damage to the open crud catcher. Raising the FAHS Bridge approximately $13 \mathrm{~cm}(5 \mathrm{in}$.) would allow an open crud catcher to clear the rails.

The effectiveness of the Kellem cable grips in preventing the grapple electrical cables from pulling on the connectors needs to be monitored during operation. It would be advantageous to put a loop in the cable between the cable grip and the connector. The loop could be observed during operation to see if the grips are effective in preventing loading of the electrical connectors. Figure 11 shows the Kellem cable grips and electrical connector location. The straight length of cable between the grip and the connector provides uncertainty concerning the loading of the electrical connector. 


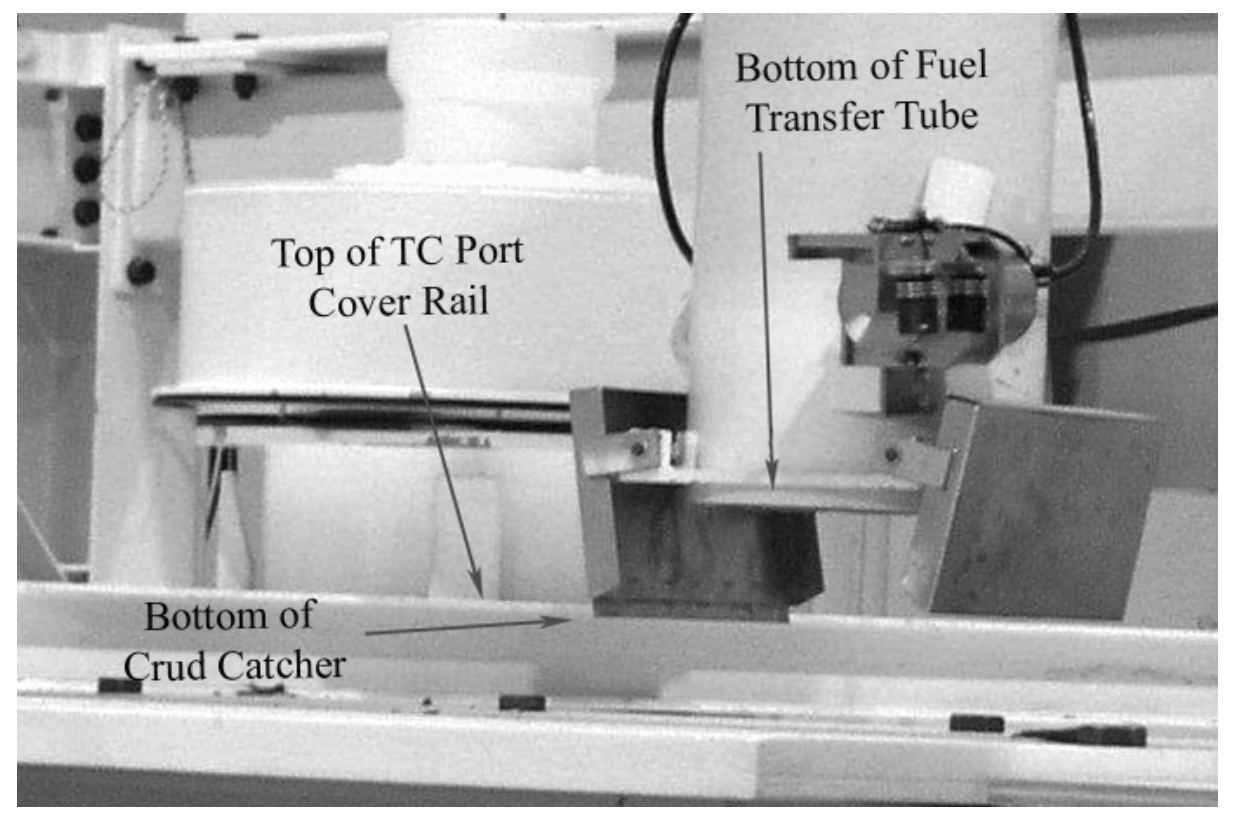

Figure 10. Interference between the open crud catcher and the TC port cover rails.

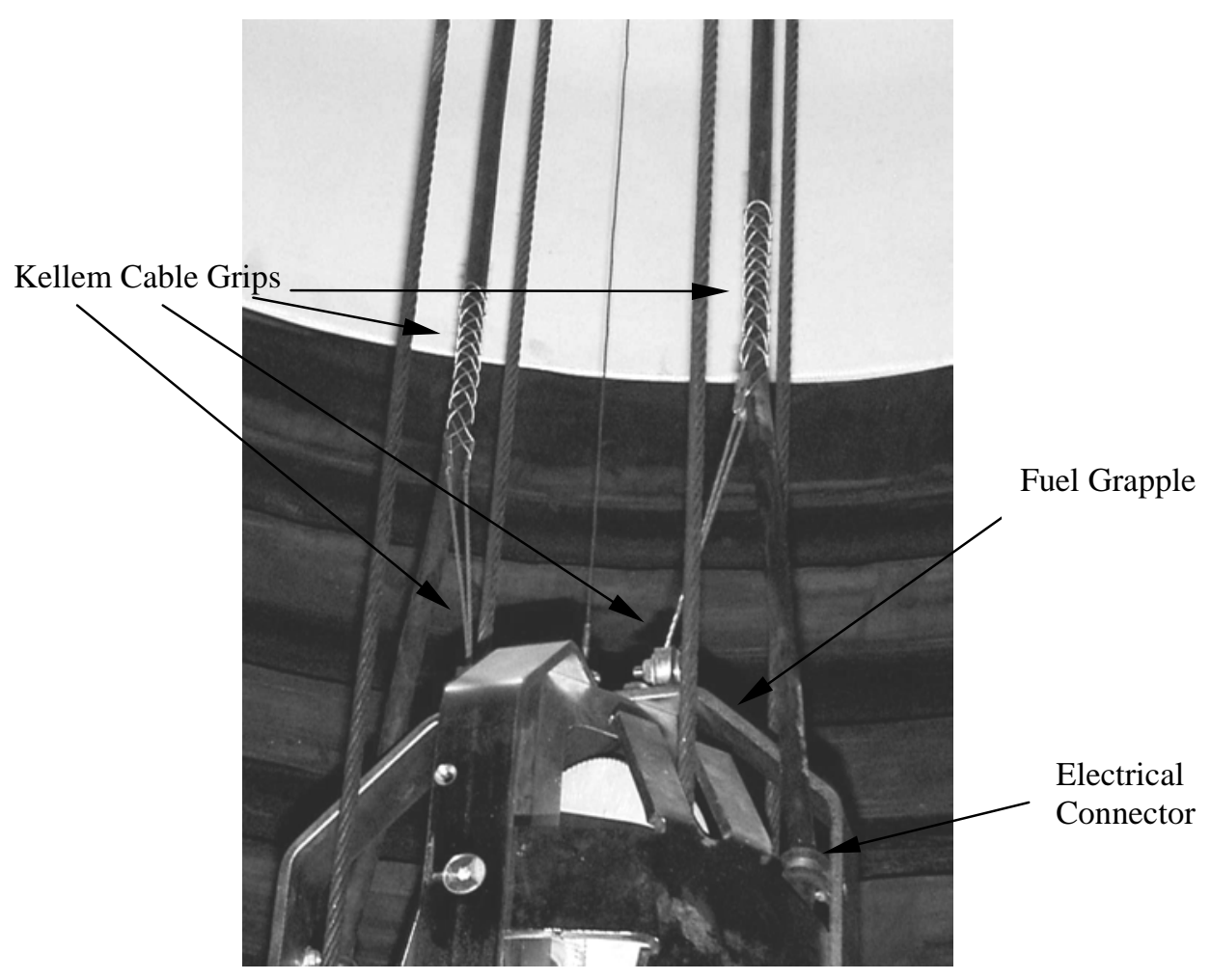

Figure 11. Kellem cable grips at the top of the fuel grapple. 
In future designs, additional consideration should be given to the internal layout of equipment control panels to protect operating staff from exposed 120 and $480 \mathrm{~V} \mathrm{AC}$ terminals. Components such as crane motor frequency drives that must be accessed for reading error messages, troubleshooting, or reprogramming, should be located for easy, safe access. Protective barriers should be placed around the exposed 480- and 120-volt terminals.

Near the end of the demonstration test, the dual-motor controllers on the FAHS crane stopped working together correctly (Figure 7). During normal operation, two hoists are used to lift a fuel element. The hoists use variable frequency vector drives with motor-mounted resolvers that provide the drives with motor shaft position information. The vector drives allow the two hoists to share the load equally. Spurious pulses generated by the resolver-to-endcoder converters caused one of the hoist cables to become slack. The slack cable would cause an alarm and halt operation, and in some instances the cable would become jammed or tangled in the sheave or grapple. As originally installed, the converters that control motor operation were powered by a five-volt supply internal to the variable-speed motor drives. The output of the hoist drive five-volt supplies was slightly above the nominal five volts (5.2 volts). The converters are rated for use with a 4.75 to 5.25 volt supply. The power supplies should have allowed the converters to work properly. Replacement of the existing converter power supplies with independent five-volt power supplies corrected the problem.

During the investigations, the signal cable shields for the encoder signals were found to be improperly grounded. Removing potential ground loops did not affect the problem. It would be prudent to focus additional attention on the FAHS crane motor encoder-to-resolver converter operation in the design of future systems.

While troubleshooting the dual hoist failure, we noticed the fuel assembly grapple fingers were working sluggishly. It was discovered that the stop bracket, item 30, NES drawing 83E8556, had moved such that it was rubbing against the cam lever, item 24, NES drawing 83E8556. Figure 12 shows the relationship between the stop bracket and the cam lever. This stop bracket is one of the two mechanical fail safe mechanisms for the grapple. As the fuel assembly grapple is lowered onto the fuel assembly, the stop bracket is raised so as to allow the cam lever to rotate under the stop bracket. If the grapple is not resting sufficiently on the fuel assembly to fully raise this stop bracket, the cam lever will strike the stop bracket. As this stop bracket is struck over and over again, it will eventually loosen the two fasteners attaching it to the push rod allowing it to move sufficiently as to preclude the operation of the cam lever and thus the operation of the grapple fingers. This failure could occur during either the engaging or disengaging of the grapple fingers. There is no recovery from this failure short of manually repositioning the stop bracket and re-tightening the fasteners. A backup means of releasing the fuel assembly should be developed.

Operation of the manual motor drives worked very well. However, care must be used when manually releasing the motor brake. The drive motor manual-brake-release pull pins are relatively easy to remove from the housing by pulling on them. They need only be pulled out $2.54 \mathrm{~cm}(1 \mathrm{inch})$ to release the brake. It would be helpful to have some system to help keep the Off-Normal recovery tool aligned with the bridge motor. If a failure occurs while the bridge is over the Source Cask, the tool must be inserted into the TC area approximately 28 feet. This distance makes it difficult to position the end of the tool on the drive nut and to hook the brake release pin.

\subsection{Shield Plug/Lid Handling Subsystem}

Several challenges were encountered in the operation of the SPHS grapple assembly. The most serious is that the SPHS grapple cannot be manually disengaged from the overlid, with the Off-Normal recovery tool, while the overlid is in the cask interface system bellows. The actuator rod for the 

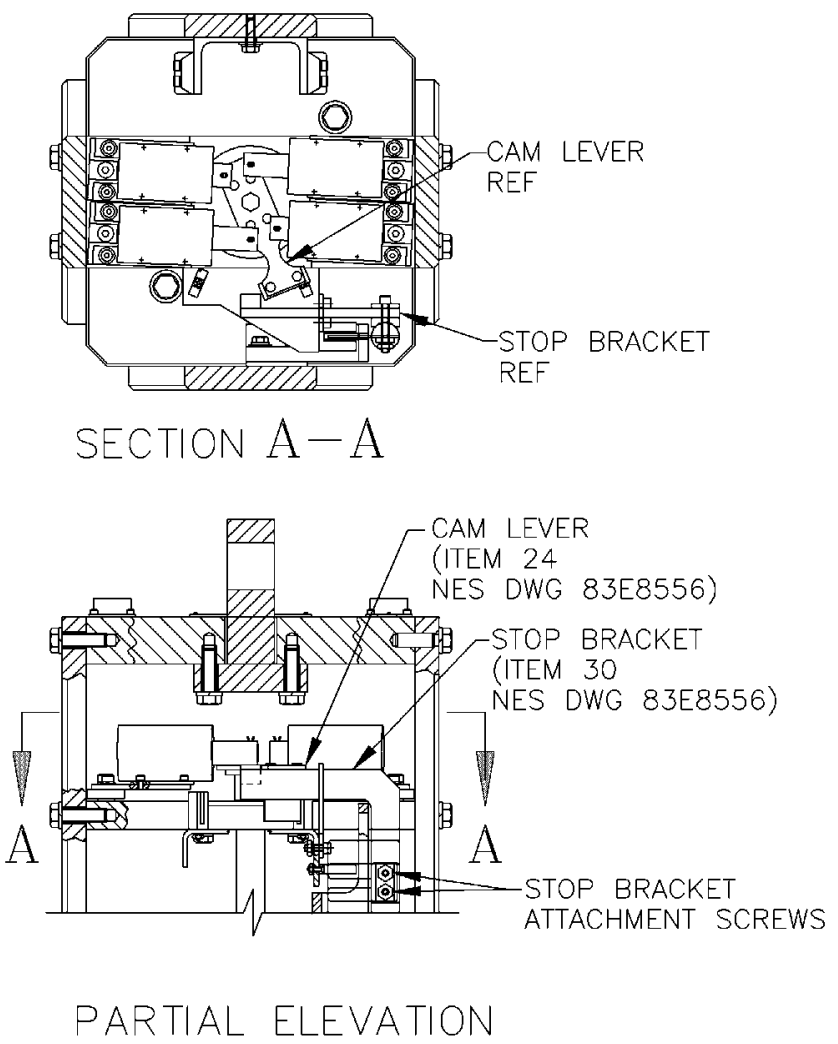

Figure 12. Fuel Assembly Handling Subsystem grapple stop bracket and cam lever relationship.

off-normal recovery mechanism is $27 \mathrm{~cm}$ (10 1/2 inches) below the top of the mezzanine floor. The position of the grapple with respect to the mezzanine floor when the grapple is in a position to remove a shield plug from the receiving cask is shown in Figure 13. This would put the access point for off-normal recovery in the bellows region below the mezzanine plate. It could not be engaged or disengaged in this location. This major design flaw must be corrected. There is sufficient room in the grapple assembly to move the off-normal recovery access point so it would be above the mezzanine floor, which would make it accessible.

Other operational challenges should also be addressed. While lifting of the shield plug, the overlid tends to twist as it is lifted off the cask or the port cover. Much of this twisting was caused by a noticeable difference in the friction between the various sheaves of the load blocks associated with the existing TAN Warm Shop overhead crane. The TAN Warm Shop crane is a 30 ton crane. This makes it extremely difficult to set the shield plug back on the cask so it meshes with alignment pins. The alignment challenge is further aggravated by operation of the grapple itself. For the grapple to engage the shield plug, all of the weight must be taken off the cables so the overlid fingers can operate without spinning the grapple assembly. Loading the cables and engaging the grapple introduce misalignment into the system. Avoidance of the use of load blocks in the design of the DTS facility upper crane may alleviate this problem.

Another impact of the grapple system operation is its effect on the control system response. When sufficient slack is allowed in the cables to ensure the entire weight of the grapple is on the overlid, the grapple assembly will tip to one side. If the grapple tips away from the "overlid present" sensor rod, the "overlid present" signal is momentarily lost. When the grapple assembly is disengaged and raised off the overlid, the overlid fingers status activation rod moves down to a position indicating the overlid fingers are open. However, the overlid fingers are still closed on the shield plug pintle. 


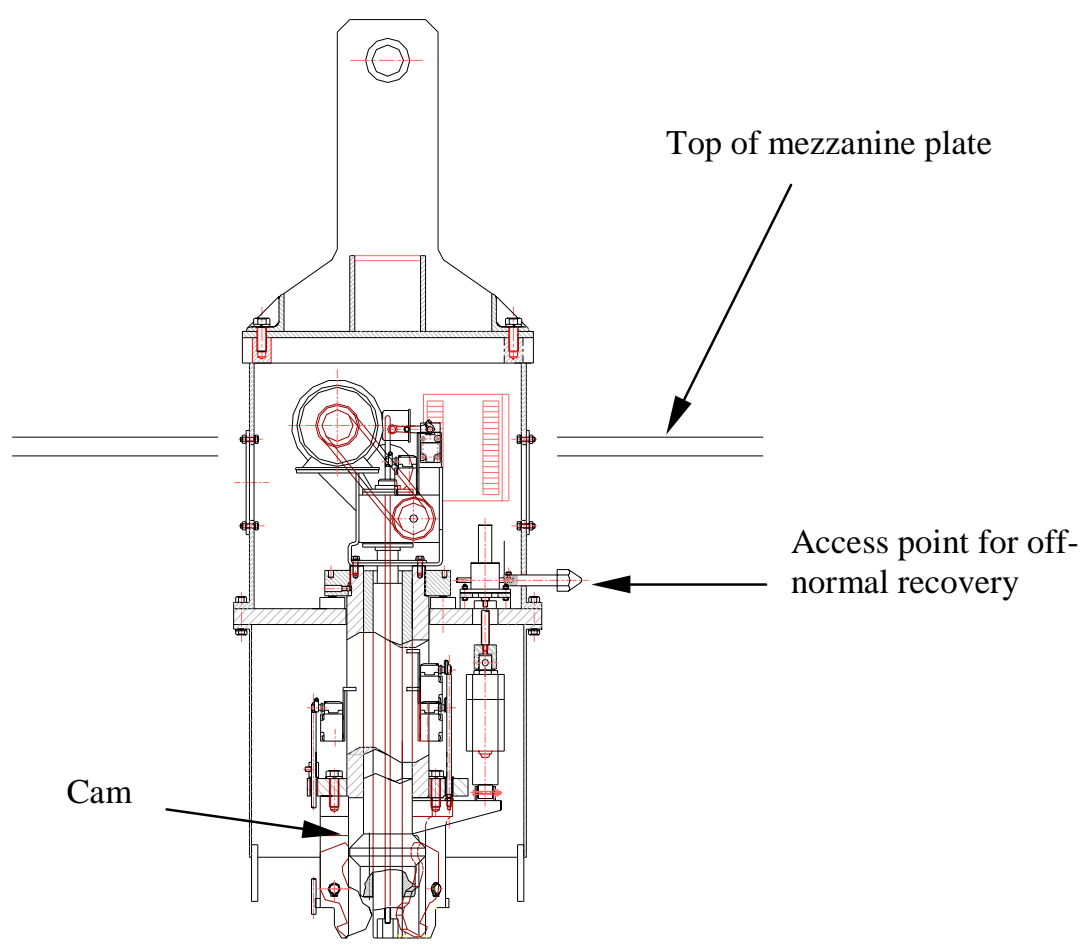

Figure 13. Shield plug/lid handling subsystem grapple assembly.

As presently designed, the SPHS can not be remotely attached to the overlid because the hex drive nut for the overlid fingers does not always self-align. The hex nut and socket need to be redesigned to be self-aligning.

It was also noted that the off-normal recovery shaft for the SPHS grapple fingers tends to rotate between 1/8 and 1/4 turn each time the grapple finger's motor is activated. Eventually, the cam and sensor rod are moved out of position and the "grapple engaged" signal does not work. If the rod is not readjusted, the cam will eventually rise enough that it will bind on the top of the fingers and prevent them from closing. Future SPHS grapples should modify the design to eliminate this problem.

The SPHS grapple should never be engaged using the Off-Normal recovery tool because in doing so, the rod connecting the grapple fingers cam actuator to the manual action jack becomes disengaged from the action jack. This should not be a problem because the grapple fingers are not normally engaged manually. If the grapple-finger cam actuator fails, the grapple assembly can be raised to the upper mezzanine area and repaired manually.

\subsection{Cask Interfacing Subsystem}

The excessive clearance between components of the CIS was designed to simplify operations of the system but was found to cause problems. The excessive clearance allowed misalignment of the cask, which prohibited removal of its shield plug. Until the bottom of the shield plug clears the top of the cask basket, its motion is limited to pure vertical movement. The top edge of the shield plug will pass or interfere with the bottom of the annular platform before the shield plug clears the top of the basket. The "as received" annular platform made it possible to have the top of the shield plug catch on the bottom of the annular platform. It was also found that the clearance between the guides on the annular platform and the overlids made it difficult to replace the shield plugs. The configuration of the cask interfacing system with respect to the cask is shown in Figure 14. 


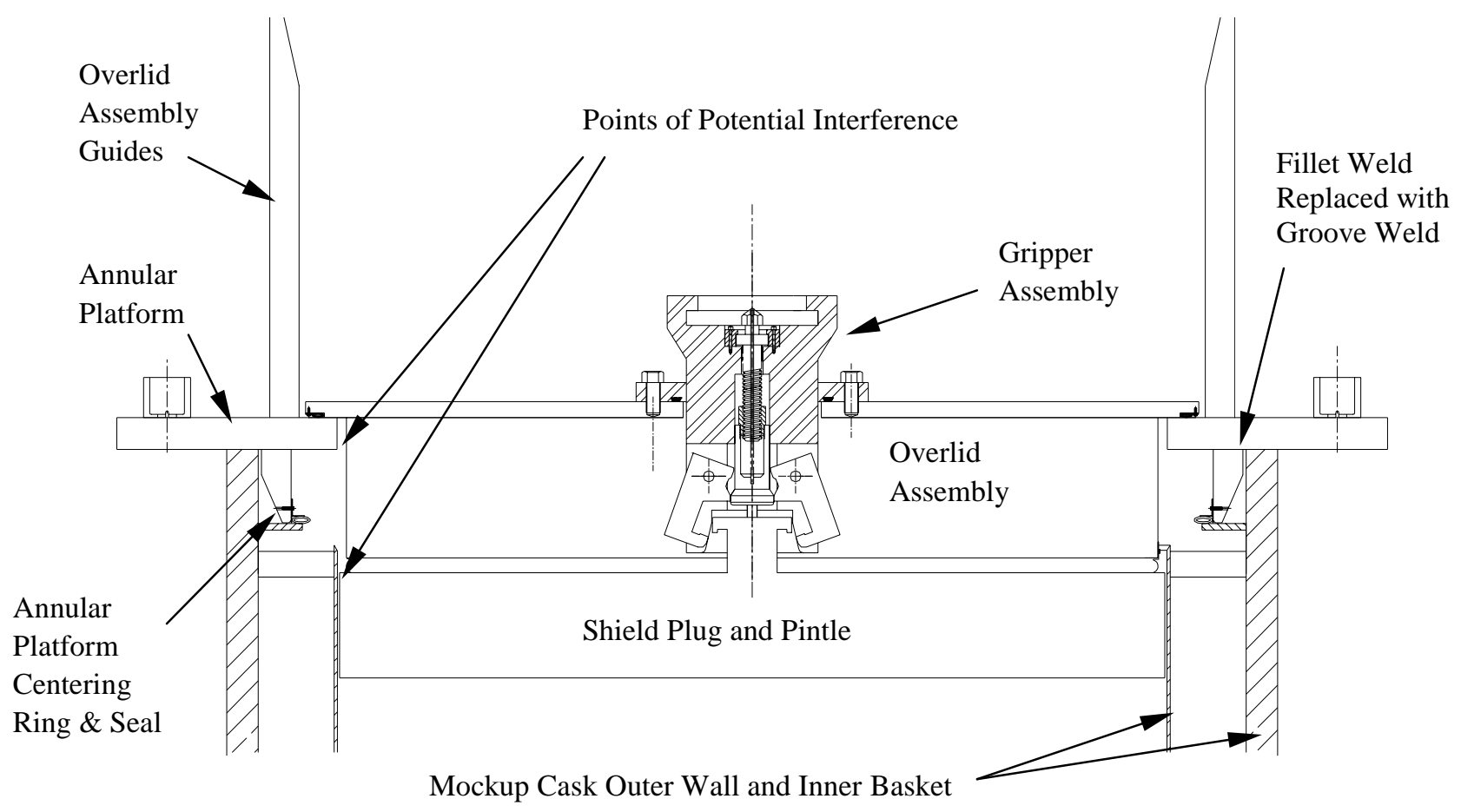

Figure 14. Cask interface system in relationship to the top of the cask.

Modifications were made to the annular platforms to enlarge the center openings and decrease the clearances between the guide bars and the overlids. Although this modification helped, it did not entirely solve the problem. In future designs, the annular platform should be designed such that when fully engaged with the cask, the center opening of the annular platform is centered with the opening of the cask. There should be no more than $1 / 8$ in clearance between the beveled guide ring on the annular platform and the cask when fully engaged. The guide bars for the overlid should be set to bring the overlid to the precise center of the annular platform. With this type of configuration, there should be no problems with removing the shield plugs from a cask that is off-centered.

The fillet welds around the outside of the centering ring on the receiver cask and the source cask annular platforms interfered with the sealing of the annular platform to the cask. The location of the weld is also pointed out in Figure 14. Replacement of the fillet welds with groove welds eliminated this interference.

It should be noted that the CIS gasket for the source cask sometimes stuck to the simulated cask and was pulled out of the groove when the bellows was retracted. This may be caused by the fact that the simulated cask is constructed of painted carbon steel. The real cask is stainless steel. Silicon RTV was added to keep it in place during the demonstration.

The "cask interfacing jacks not extended" alarm did not activate when a simulated obstruction was placed on the cask to prevent the annular platform from interfacing with the cask. The control system receives information on the pressure exerted by the jack from the load cells. When the control system senses the predetermined load cell pressure setpoint, movement of the jack(s) is stopped. The setpoint pressure is reached wherever the obstruction or the cask seal stops the jack. The control system also receives signals from position locators associated with the screw jacks. To distinguish between an obstruction (send an alarm) and the cask seal (successful completion of action), the control system must 
know the position of the jack relative to the cask lid within $\pm 1 / 4$ in. The position-sensing equipment measures the distance relative to the mezzanine plate, not the cask, which can vary with different casks. The position indicators, as designed and supplied, do not allow measuring the required parameters within the accuracy required to correctly control the system. The control system also does not use the two signals together.

During testing of the Cask Interfacing System in the off-centered position, the three electric cylinders (screw jacks) on the Source Cask started to unthread the "optional threaded end" of the Actionjac electric cylinders from the load cell clevises. One "optional threaded end" actually unthreaded to the point where the remaining threads were stripped and the annular platform fell approximately $15 \mathrm{~cm}$ (6 inches) onto the simulated cask.

The "optional threaded end" is a machined round bar threaded on both ends. The diameters of the threaded ends are of different sizes. The larger end threads into the end of the Actionjac electric cyclinder and is secured by two set screws. The smaller threaded end is for attaching a customer supplied device. In the DTS application, this device was a load cell clevis foot.

Upon investigation, the two set screws, designed to keep the "optional threaded end" from disengaging from the end of the cylinder, were found to be loose. However, this was not the end that failed. There was no set screw or roll pin included in the CIS vendor's design to keep the "optional threaded end" from disengaging from the load cell clevis foot. Following replacement of the failed part, roll pins were added to all electric cylinders to prevent this from occurring again.

What exactly caused the "optional threaded end" to unthread from the load cell clevis foot is not known. Since unthreading of the electric cylinder did not happen on the Receiver Cask or at any other time except while the Source Cask was off-set $7.6 \mathrm{~cm}$ (3 inches) from center, it is speculated that positioning the electrical cylinders on an angle placed them in a bind. Prior to the load cell set point being reached, the annular platform would make contact with the simulated cask and further physical extension of the electric cylinder would be stopped. Since the electric cylinder is still operating and the internal screw still turning, the outer cylinder would simply start to move back up the internal screw. This movement of the outer cylinder is the same rotational direction required to unthread the load cell clevis foot.

\subsection{Closed-Circuit Television Subsystem}

Several overview camera positions were tried during the demonstration. The best distribution of cameras was one on each end of the transfer confinement area and two on each side, centered with the cask ports. This provides six cameras, four of which are shown in Figure 3.

The camera positions noted in the Conceptual Design Report (Dawson et al. 1995) must be recessed in the wall or the cable festoons must be moved. In the Conceptual Design, the cable festoons for the Fuel Assembly Handling System are set at the outside of the bridge and will make contact with anything hung on the walls.

It was necessary to have a labeled floor plan of the transfer confinement area in front of the operation technicians to help with orientation. While positioning the FAHS over a simulated fuel assembly, it would get confusing as to which way to move the bridge or trolley. There are no reference points on the casks to tell the operation technicians which way is North or East. 


\subsection{Off-Normal Recovery Subsystem}

Design considerations associated with off-normal recovery were addressed within each of the individual DTS subsystem sections. The off-normal recovery access points shown in Dawson et al. (1995) generally are the best locations. The actual dimensions for locating these access ports must be coordinated with the final design to line up with the height of the motors and the centers of the cask ports.

It is noted here that upon failure of both fuel assembly handling system hoists, the fuel assembly can be lowered manually. The rate of decent for the fuel assembly when both system hoist brakes are released and the fuel assembly is allowed to fall freely is $1 \mathrm{~m} / \mathrm{min}$ ( $3 \mathrm{ft} / \mathrm{min})$. An individual grabbing the hoist drive nut of one hoist system and preventing it from rotating can easily stop decent of the fuel assembly. The weight of the fuel assembly grapple, without the fuel assembly attached, is not sufficient to cause the grapple to descend. In this case the hoist drives must be manually turned to lower the grapple.

\subsection{Miscellaneous Comments}

The fuel assembly grapple can only be lowered into the cask canister opening approximately $20 \mathrm{~cm}$ (8 inches). The four plates used to attach the grapple to the load block are wider than the fuel assembly openings in the cask canisters. Thus, while trying to lower the grapple further into the cask, the load block and grapple rested on the top of the canister and the hoists continued to unwind. An "unwind" alarm was received. They were allowed to continue to unwind because the lower limit switch was set so the grapple could be lowered to the floor when a cask is not in position. This setting allows the fuel assembly crane to be disassembled and reassembled. A caution should be added in the Operations and Maintenance Manual to set new parameters if the type of cask or the setpoint is changed to allow the grapple to be lowered to the floor. The addition of the Engineering Screen to the control system made it possible to change this lower limit switch setting relatively easy.

\subsection{System Upgrades Resulting from the Demonstration}

The following improvements were made to the system as results of the demonstration:

- $\quad$ The center opening was increased to allow removal of shield plug when off-centered. The impact of this modification was discussed in Section 5.6. Basically, the modification helped but did not entirely solve the problem.

- A development key was purchased for the control system software to allow the user to change screen make-up. The development key allows the user to edit and maintain the software (see Section 5.4).

- $\quad$ An engineering screen was added that displays actual setpoints and allows these setpoints to be changed. Two engineering screens were added to allow the operator to view the current settings for limits and allows the limits to be changed (see Section 5.4).

- An Input/Output screen was added to display actual sensor signals as an aid in troubleshooting (see Section 5.4). The color of the sensor indicates if it is active or not.

- $\quad$ The control system alarm message display was enhanced to help in troubleshooting and identifying possible causes of the alarms (see Section 5.4). 


\subsection{System Throughput}

The various operations demonstrated at the INEEL were timed to provide an estimation of the time involved in transferring fuel assemblies. An average of 40 minutes is required for a complete fuel assembly transfer cycle. This cycle begins with the FAHS centered over the source cask. The fuel assembly transfer cycle consists of the following activities:

1. Opening the crud catcher doors

2. Lowering the fuel assembly grapple and retrieving the fuel assembly

3. Closing the crud catcher doors

4. Moving the FAHS to the receiver cask

5. Opening the crud catcher doors

6. Placing the fuel assembly into the receiver cask

7. Closing the crud catcher doors

8. Returning the FAHS back to the source cask.

The time involved in transferring fuel assemblies from one cask to another will vary depending on operator skills, retrieval and placement locations of the fuel assembly, and fuel assembly accountability and verification processes. This time is based on retrieval and placement of the fuel assembly with a hoist speed of $1 \mathrm{~m} / \mathrm{min}$ (40 inches/min). The fuel grapple hoist travel speed can be changed.

Other timed actions demonstrated at the INEEL include the following:

1. Interfacing the source CIS to the source cask $=1$ minute 10 seconds.

2. Interfacing the receiver CIS to the receiver cask $=1$ minute 10 seconds.

3. Open the source cask TC port cover door $=37$ seconds.

4. Lock the source cask TC port cover door $=5$ seconds.

5. Open the receiver cask TC port cover door $=2$ minutes 10 seconds.

6. Lock the receiver cask TC port cover door $=5$ seconds.

7. Move the FAHS from the parked position to the source cask $=1$ minute 35 seconds.

8. Move the FAHS from the receiver cask position to the parked position $=1$ minute 35 seconds. 


\section{CONCLUSION AND RECOMMENDATIONS}

\subsection{Conclusion}

The demonstration test deliberately challenged the system to determine whether any activities could jeopardize the activities of another function or the safety of the system. All known interlocks were challenged. Following system modifications, additional testing was performed to validate the modifications. In general, all the equipment worked exceptionally well; it ran smoothly and functioned as designed. As in all new systems, a few "bugs" had to be corrected.

Design drawings were updated to reflect the hardware as-built configuration. The hardware and drawing changes described in this report were independently verified to be correct.

\subsection{Recommendations}

The recommendations have been divided into three groups, those that must be made to ensure safe operation of the system, those that should be made to enhance the operation of the system, and those that could be made but are not critical to system operation.

Recommendations that must be made to ensure safe operation of the system:

- $\quad$ The FAHS bridge needs to be raised approximately $13 \mathrm{~cm}$ (5 inches) to allow the crud catcher to clear the port cover rails in the event of a crud catcher failure. Now, when the crud catcher is open, it extends low enough to contact the transfer confinement port cover rails if the crane travels over them.

- The position indicator sensor needs to be located below the emergency cable release for the crud catcher so that the control system can monitor the true position of the crud catcher. Currently, when the crud catcher emergency cable release is activated, the control system is not aware that the crud catcher is hanging open because the sensor is above the release mechanism.

- A spring or other mechanism needs to be added to the lower actuator pin to ensure that the crud catcher doors fail in the fully open position. If the crud catcher jams or fails and cannot be opened, the fuel assembly can be lowered through the crud catcher, tripping the breakaway pin-socket assembly. Because the crud catcher doors do not fail in the fully open position, the fuel assembly grapple cannot be retracted into the transfer tube because the grapple catches the partially closed crud catcher doors.

- $\quad$ The FAHS grapple should be redesigned so it can be opened or closed when resting on the fuel element. The redesign could also address elimination of grapple twist under load. It may help to fit the crane with a telescoping tube to stabilize the grapple.

- $\quad$ Routine maintenance should involve checking the position of the cam stop bracket. Reference Figure 12.

- $\quad$ There is no way of performing preventative maintenance on the fuel assembly hoist cables without complete disassembly. During disassembly of the system it was discovered that at some time the fuel assembly grapple load block had been raised sufficiently to crunch the 
cables at the clevis wedge. No metal wires were broken, however, the center fiber core was damaged. There is no way to view the last $4.6-\mathrm{m}(15 \mathrm{ft})$ or so of the hoist cables.

- $\quad$ The SPHS grapples need to be redesigned to eliminate misalignment of the shield lid after lifting, to eliminate rotation of the grapple fingers each time the finger's motor is activated, and to permit off-normal recovery when the grapple is in the bellows area of the CIS.

- The overlid fingers hex drive on the shield plug/lid handling subsystem needs to be redesigned to allow the drive nut to be self-centering.

- $\quad$ A shaft lock needs to be added to the off-normal recovery drive shaft for the grapple fingers of the shield plug/lid handling subsystem so they do not move out of position and lock up the fingers.

The following are recommendations that should be made to enhance operation of the system:

- A cover needs to be provided for the fuel grapple actuating mechanism to prevent catching a hoist lifting cable between the grapple and the transfer tube. In the caught position, the cable can damage the moving grapple parts.

- $\quad$ The fuel assembly grapple load block sheave guards need to be redesigned to remove the excess space between the guards and the sheave. There is sufficient clearance between the guard/guide and the sheave to allow the cable, if it is slack, to move off the sheave and onto the sheave shaft.

- The electric cable routing scheme should be revised, including provisions to segregate power and control signals, reduce excess and loose cable, and better support the cables. In addition, high-intensity interference sources such as welding should be controlled by administrative actions during operation of the DTS equipment. In the test configuration at the INEEL, the power source for the DTS equipment was supplied from the same motor control center as an automatic weld machine in the same shop. Signal noise was experienced when a weld machine was operated in the Warm Shop at the same time as the DTS was being operated.

- $\quad$ Six cameras need to be used in the TC area, one on each end and two on each side, centered with the cask ports.

- The program logic should be revised to have the fuel handling crane coordinates screen come up with existing setpoints displayed. It presently comes up showing zeros for all coordinates.

- A table of interlocks (including ladder logic program line number) and a table of alarms (including action, response time, message, and ladder logic line number) should be prepared and included in the Operations and Maintenance Manual.

- A troubleshooting table should be compiled so that when an alarm is received, the operator can look in the table and see what the probable causes are. The alarm message on the screen is sometimes too vague, it does not always provide this information.

- $\quad$ A backup means should be provided to release fuel from the grapple. 
- $\quad$ Nonconductive shields should be installed on the exposed 480 and $120 \mathrm{~V}$ AC components. Other power and signal circuits should be arranged to minimize exposure to high-voltage components when the panel is opened.

- $\quad$ Power circuits should be installed in separate panels from the signal circuits when possible.

- An evaluation of signal impact on control systems and accurate weight should be made. The FAHS crane load weight is calculated by using the output of two load cells, one on each cable. The highest reading signal is sent to the computer control system and the other is ignored. As the load shifts between the cables, due to swinging and the load sharing of the two crane motors, the calculated weight fluctuates constantly. The load weight is normally accurate when the crane and load are not moving. This may be the cause of numerous spurious signals and alarms such as the "fuel assembly underweight/overweight" alarms received during operation. Similar fluctuations occur in the SPHS grapple.

- $\quad$ The FAHS grapple electrical cable restraints should be evaluated for loads they may allow to be imposed on connectors. The cable restraints should be readjusted to provide a loop of cable at the connector end, and the loop of cable should be observed to see if the cable restraints allow the cable to move gradually after repeated hoisting operations.

- The actuator bracket for the transfer confinement port cover actuators should be raised so the actuators can be installed in a level position.

- A caution should be added in the Operations and Maintenance Manual to set new parameters when the type of cask is changed.

- $\quad$ Shoulder bolts are needed on the TC port cover locking pins.

The following recommendation should be considered to be of lower priority than those above.

- $\quad$ Care needs to be taken by the operator so the hoist cables are not unwound.

- $\quad$ Provisions should be made to seal the lifting eyebolts holes on the source cask mezzanine plates after assembly to preclude radioactive contamination during operation. The location of the bolt holes should be included on the design drawings.

- $\quad$ Provisions should be made for the control system to store multiple set points in memory. They should be easy for the operator to enter, store, and retrieve.

- $\quad$ The use and designation of critical versus non-critical alarms should be reviewed and designations clarified.

- Software should allow both source and receiving TC port covers to operate at the same time to save operating time. This may require modification to control system screen content to combine the source and receiving cask screens for the TC port covers and cask interfacing systems.

- An evaluation should be made of the need for the "alarm acknowledge" function..

Acknowledging an alarm has no effect except to turn the alarm text green. It should be eliminated if it is not useful. 
- If additional systems are built, the system integrator should insist that the vendors coordinate to fix the error message problem on startup. The current system receives six errors on every startup (bridge, trolley and secondary hoist, over and under travel alarms).

- $\quad$ Kits should be purchased from the manufacturer and installed to mount the digital control modules on the cabinet door so that they are accessible without opening the control panel or shields should be placed over the exposed high voltage hazards in the cabinets. (Caution: There may be disadvantages to having the drive controls available to anyone in the room without strong administrative controls.) In future designs, the frequency drives should be mounted so that the control module keypad and display are accessible without opening the control panel. 


\section{REFERENCES}

Dawson, D. M., G. Guerra, T. Neider, and P. Shih, 1995, Dry Transfer System for Spent Fuel: Project Report, EPRI TR-105570, Electric Power Research Institute, Palo Alto, California.

EPRI, 1989, Design Considerations for On-Site Transfer Systems, EPRI NP-6425, Electric Power Research Institute, Palo Alto, California.

Gili J., 1998, Dry Transfer System Demonstration Test, Technical Procedure TPR-1205 Revision 1, TAN Operations, Lockheed Martin Idaho Technologies Company, Idaho Falls, Idaho.

Pennington, C. W., T. J. Neider, G. V. Guerra, and K. V. Margotta, 1991, Conceptual Design for an On-Site Spent-Fuel Transfer System, EPRI NP-7459, Electric Power Research Institute, Palo Alto, California.

U.S. Department of Energy, 1996, Dry Transfer System, Topical Safety Analysis Report, Volumes 1 to 3, U.S. Department of Energy, Office of Civilian Radioactive Waste Management (U.S. NRC Docket No. 07201024). 


\section{Appendix A \\ Comparison of DTS Demonstrated at INEEL and the EPRI DTS}




\section{Appendix A \\ Comparison of DTS Demonstrated at INEEL and the EPRI DTS}

In this appendix, the EPRI system refers to the DTS designed by TN and documented in the EPRI design report (Dawson et al. 1995). The demonstrated DTS prototype system is based on specifications developed for the INEEL by FDI on the basis of the EPRI design report.

\section{INTRODUCTION}

- $\quad$ The EPRI system (Dawson et al. 1995) used the B\&W $15 \times 15$ PWR fuel assembly for the design basis. The DTS demonstration project used the Westinghouse $15 \times 15$ fuel assembly because this fuel was available at INEEL for a hot demonstration. The fuel-handling crane was designed for enveloping a full-length fuel assembly (length, cross-section, and weight of fuel and grapple).

- $\quad$ At INEEL, the TN-8L cask was used as the basis for the mock-up source cask and TN West (formerly Vectra) NUHOMS ${ }^{\circledR} 24 \mathrm{P}$ dry shielded canister and MP-187 cask were used as the basis for the mock-up receiver cask instead of those used as design basis for the EPRI DTS. The change in fuel assemblies and casks was based on the fact that there were TMI-2 fuel assemblies in the storage pool at TAN at INEEL that were scheduled to be transferred to dry storage as a milestone in a court order agreement between the State of Idaho and DOE. At the time of the decision, the project schedule coincided with the TAN schedule to have a TN-8L cask and a NUHOMS MP-187 cask available for the hot demonstration. TAN also had a simulated Westinghouse $15 \times 15$ array PWR fuel assembly available for use in the cold demonstration.

- $\quad$ The location of the wall penetrations for emergency backup operations using long-reach tools is different in the two designs. TN, EPRI's designer, agreed that the current penetrations may not be located where required and may not be sufficient for all backup operations. Transnuclear had not considered release of the motor brakes in the EPRI design.

- $\quad$ Some component sizes (beam sizes) were specified in the EPRI system (Dawson et al. 1995). For the demonstration at INEEL, FDI left the size of the components up to the vendor to determine.

- $\quad$ The DTS demonstration equipment was also supported on a test frame instead of EPRI's concrete structure.

- The demonstration DTS used a $0.7 \mathrm{~g}$ seismic design spectrum in both the $\mathrm{x}$ and $\mathrm{y}$ directions. This was required to meet INEEL seismic requirements for the support frame. This design encompasses the EPRI design.

\section{FUEL ASSEMBLY HANDLING SUBSYSTEM}

- The EPRI design has a larger envelope diameter for the crud catcher, cameras, and lighting at the end of the fuel transfer tube. The DTS demonstrated was designed for the same cask shielding structure inner footprint but a larger receiving cask shield plug. There is less space available to clear interference. 
- $\quad$ The EPRI system has limit switch ZASL-110 coupled with the primary hoist to stop the fuel handling crane at low load elevation. This switch is considered optional with the INEEL DTS because it would be ineffective when using the second hoist.

- $\quad$ The location and design of the three supports for each rail assembly is different in the two designs. The center location is the same with slightly different locations at each end. Changes were made to improve the design.

- $\quad$ The demonstrated DTS used a 12-in. grapple outer diameter to ensure that there would be no interference between the grapple and the cask/canister for smaller fuel assemblies that may be off-center in the cell. The EPRI design had a 13-in. grapple outer diameter.

\section{CASK INTERFACING SUBSYSTEM}

- $\quad$ The demonstrated DTS cask interfacing system was designed for use with a TN-8L source cask and an MP-187 cask/24P canister receiver cask. The design-basis cask used for the EPRI system was the hypothetical multipurpose canister (MPC).

- $\quad$ The EPRI system used mezzanine plates machined to overlap at the bolts to the support structure. The mezzanine plates for the demonstrated DTS are designed to be individually bolted to the support structure.

- $\quad$ The EPRI system classified the mezzanine plates as important to safety. They were declassified in the DTS demonstrated.

- $\quad$ The EPRI system called for reusable mezzanine support plates. The supports used for the DTS demonstration are an integral part of the support structure. This fact did not change the design of the mezzanine plates.

\section{CASK OVERLIDS}

- $\quad$ The overlids specified in the EPRI system were designed for hypothetical source and receiving casks. The pintle attached directly to the lid/shield plug. To accommodate the configuration of the lid and shield plug on the actual cask (e.g., irregular sealing surfaces and lack of pintle attachment provisions), an adapter plate was used for each cask in the demonstration.

- The EPRI system specified a three-position cam system for gripper finger operation (open, closed, set seal). A two-position cam system for the gripper finger operation (open, closed) was used in the DTS demonstration project. A static bulb seal between the overlid and the shield plug is designed to accommodate the tolerance range of shield plug positioning in the cask. The third cam position (set seal) is not required. This eliminates a costly, high-maintenance spring plate from the grippers. The change also significantly reduces the capacity of the drive screw system in the overlid grapple from lifting the shield plug to simply actuating the gripper fingers.

\section{OVERLID GRAPPLE}

- The EPRI system specifies a dedicated upper crane for use in removing the shield plug/lid. The upper crane was not in the scope of the DTS demonstration project. Instead, the grapple assembly used an adapter to attach it to the existing building overhead crane for the demonstration test. 
- The EPRI design specified a three-position sensor (ZL315A/B/C) to match the three-position cam system. A two-position sensor is required to match the two-position cam system used in the DTS demonstration project design.

- In the INEEL DTS, the transfer confinement port cover locking pins were moved from the port covers to under the mezzanine plates. This eliminated the need for traveling power and instrument cables in the high radiation environment of the transfer confinement area and provided additional space for a larger overlid on the receiving cask transfer confinement port cover.

- In the INEEL DTS, the transfer confinement port cover overtravel limit switches were eliminated.

\section{CONTROL SYSTEM}

- The EPRI design has a complete control system with interlocks. The control system used for the DTS demonstration project limited the controls actually developed to those required for operation of the equipment to be demonstrated. Interlocks for equipment not demonstrated were not simulated. The specified size of the control system does allow additional controls and interlocks to be added to accommodate the complete system detailed by EPRI.

\section{QUALITY ASSURANCE}

- NQA-1 was the quality assurance program specified in the EPRI design. The DTS demonstration project incorporated the DOE/RW-0333P quality assurance program.

\section{ALARMS}

The following table compares the alarms specified in the EPRI design with the alarms actually implemented in the DTS demonstrated at INEEL. If there are no comments indicated in the "comments" section, the alarm was implemented without change.

Table A-1. Alarms from the EPRI design that were included in the DTS demonstration.

\begin{tabular}{|c|c|c|}
\hline $\begin{array}{l}\text { EPRI Test } \\
\quad \text { Plan } \\
\end{array}$ & Description, from EPRI Design & $\begin{array}{l}\text { Comments, Demonstration System } \\
\text { Deviations from the EPRI Design }\end{array}$ \\
\hline 1 & $\begin{array}{l}\text { Emergency pushbutton activated } \\
\text { (main) }\end{array}$ & - \\
\hline 2 & $\begin{array}{l}\text { Emergency pushbutton activated } \\
\text { (remote) }\end{array}$ & - \\
\hline 3 & $\begin{array}{l}\text { Programmable logic controller } \\
\text { hardware malfunction }\end{array}$ & Not implemented by Vision, no input signals available. \\
\hline 4 & $\begin{array}{l}\text { Source and receiving cask interfacing } \\
\text { jacks not extended. }\end{array}$ & $\begin{array}{l}\text { Expanded to multiple alarms: } \\
\text { Source cask interfacing jack \#1 not extended. } \\
\text { Source cask interfacing jack \#2 not extended. } \\
\text { Source cask interfacing jack \#3 not extended. } \\
\text { Receiving cask-interfacing jack \#1 not extended. } \\
\text { Receiving cask-interfacing jack \#2 not extended. } \\
\text { Receiving cask-interfacing jack \#3 not extended. }\end{array}$ \\
\hline
\end{tabular}


Table A-1. (continued).

\begin{tabular}{ccc}
$\begin{array}{l}\text { EPRI Test } \\
\text { Plan }\end{array}$ & Description, from EPRI Design & $\begin{array}{c}\text { Comments, Demonstration System } \\
\text { Deviations from the EPRI Design }\end{array}$ \\
\hline
\end{tabular}

$5 \quad$ Source and receiving cask interfacing jacks not retracted.

6
Cask interfacing load cell exceeded maximum allowable weight

Source and receiving, jacks will not seat (jacks 1,2,3,)

Cask interfacing load cell exceeded minimum allowable weight

Source and receiving transfer confinement port covers will not open.

Source and receiving transfer confinement port covers will not close.

Source and receiving transfer confinement port cover will not lock.

Source and receiving transfer confinement port covers will not unlock.

Receiving cask lockpin position malfunction

Source cask lockpin position malfunction

Overlid grapple will not open.

Overlid grapple will not close.

Cask overlid cover will not close.

Cask overlid cover will not open.

Grapple weight malfunction.

Transfer confinement port cover motor contactor failed to close.

Cask interfacing motor contactor failed to close.

Fuel handling motor contactor failed to close.
Expanded to multiple alarms:

Source cask interfacing jack \#1 not retracted.

Source cask interfacing jack \#2 not retracted.

Source cask interfacing jack \#3 not retracted.

Receiving cask-interfacing jack \#1 not retracted.

Receiving cask-interfacing jack \#2 not retracted.

Receiving cask-interfacing jack \#3 not retracted.

Not implemented by Vision, no input signals available.

Not required, minimum consequences and condition easily recognized by operator on control screen.

Not implemented by Vision, no input signals available.

Expanded to multiple alarms:

Source transfer confinement port cover will not open.

Receiving transfer confinement port cover will not open.

Expanded to multiple alarms:

Source transfer confinement port cover will not close.

Receiving transfer confinement port cover will not close.

Expanded to multiple alarms:

Source transfer confinement port cover will not lock. Receiving transfer confinement port cover will not lock.

Expanded to multiple alarms:

Source transfer confinement port cover will not unlock.

Receiving transfer confinement port cover will not unlock.

Not implemented, no input signal available. Not required, redundant with alarms 11 and 12 .

Not implemented; no input signal available. Not required, redundant with alarms 11 and 12 .

Clarified, changed to overlid grapple fingers will not open.

Clarified, changed to overlid grapple fingers will not close.

Clarified, changed to cask overlid fingers will not close.

Clarified, changed to cask overlid fingers will not open.

Not implemented by Vision, no input signals available.

Not implemented by Vision, no input signals available.

Not implemented by Vision, no input signals available.

Not implemented by Vision, no input signals available. 
Table A-1. (continued).

\begin{tabular}{ccc}
$\begin{array}{c}\text { EPRI Test } \\
\text { Plan }\end{array}$ & Description, from EPRI Design & $\begin{array}{c}\text { Comments, Demonstration System } \\
\text { Deviations from the EPRI Design }\end{array}$ \\
\hline
\end{tabular}

23 Fuel handling crane will not position properly.

Overlid grapple weighing system malfunction.

Fuel handling crane hoist/grapple control malfunction.

New

New
Bridge overtravel alarm (advance).

Bridge undertravel alarm (retreat).

Trolley overtravel alarm (advance).

Trolley undertravel alarm (retreat).

Fuel load overtravel high (advance).

Fuel load overtravel low (retreat).

Fuel load overweight.

Fuel load underweight.

Main hoist overspeed.

Main hoist rope unlevel wind.

Backup hoist rope unlevel wind.

Backup hoist overspeed.

SPHS grapple underload.

SPHS grapple overload.

Rotating platform CW overtravel.

Rotating platform CCW overtravel.
Expanded to multiple alarms:

Bridge fail to advance

Bridge fail to retreat

Bridge drive fault

Trolley fail to advance

Trolley fail to retreat

Trolley drive fault

Fail to rotate $\mathrm{CW}$

Fail to rotate $\mathrm{CCW}$

Rotate drive fault.

Not implemented by Vision, no input signals available.

Expanded to multiple alarms:

Fuel handling crane grapple fail to open.

Fuel handling crane grapple fail to close.

Fuel handling crane hoist fail to lower.

Fuel handling crane hoist fail to raise.

Fuel handling crane hoist main drive fault.

Fuel handling crane hoist backup drive fault.

Fuel handling crane crud catcher failed to open.

Fuel handling crane crud catcher failed to close. 


\section{INTERLOCKS}

Table A-2 compares the alarms specified in the EPRI system with the alarms actually implemented in the DTS design. No comments indicated in the "comments" section indicate alarm was implemented without change.

Table A-2. Interlocks from the EPRI design that were included in the DTS demonstration.

\begin{tabular}{cll}
$\begin{array}{c}\text { EPRI Test } \\
\text { Plan }\end{array}$ & Description, from EPRI Design & $\begin{array}{l}\text { Comment, Demonstration System } \\
\text { Deviations from the EPRI Design }\end{array}$ \\
\hline
\end{tabular}

$1 \quad$ Verify that the fuel assembly handling crane carriage (bridge and trolley) cannot be moved unless the crud catcher is closed and the fuel assembly grapple is in its upper $\mathrm{z}$ position.

2 Verify that the rotating platform cannot be moved unless the crud catcher is closed and the fuel assembly grapple is in its upper $\mathrm{z}$ position.

3 Verify that the grapple of the fuel assembly handling hoist system cannot be lowered unless the crud catcher is open.

Verify that the transfer confinement port cover cannot be unlocked or moved when the fuel assembly handling crane carriage is in motion.

Verify that the crud catcher cannot be opened when the fuel assembly handling crane carriage is in motion.

Verify that the crud catcher cannot be closed unless the fuel assembly grapple is in its upper $\mathrm{z}$ position.

Verify that the fuel assembly grapple cannot be lowered when the fuel assembly handling crane carriage is in motion.

Verify that a fuel assembly cannot be lifted if the fuel assembly handling grapple is not totally connected or disconnected.

Verify that the receiving and source
Not implemented. Program was modified to allow operation in slow speed only, since crane must be moved when lining up with cask position.

Not implemented. Program was modified to allow operation in slow speed only, since crane must be moved when lining up with cask position. cask transfer confinement port covers cannot be unlocked or closed if the fuel assembly handling grapple is engaged.

This interlock was not implemented. A new interlock, "Source or receiving cask transfer confinement port covers cannot be unlocked or moved if the FAHS crane is not in the Park position" prevents any possibility of closing the cover on the grapple or a fuel assembly. This will allow the covers to be closed with a fuel assembly loaded on the FAHS if the FAHS is moved to the Park position. 
Table A-2. (continued).

$\begin{array}{cl}\begin{array}{c}\text { EPRI Test } \\ \text { Plan }\end{array} & \text { Description, from EPRI Design }\end{array} \begin{aligned} & \text { Comment, Demonstration System } \\ & \text { Deviations from the EPRI Design }\end{aligned}$

10

Verify that the fuel assembly cannot be removed from the grapple unless the grapple is in the proper position and the hoist is unloaded.

Verify that the transfer confinement port covers cannot be unlocked or moved when the fuel assembly-handling hoist is loaded.

12 Verify that lid/shield plug handling grapple cannot be lifted unless the grapple is fully connected or fully disconnected.
This interlock was not implemented. A new interlock, "Source or receiving cask transfer confinement port covers cannot be unlocked or moved if the FAHS crane is not in the Park position" prevents any possibility of closing the cover on the grapple or a fuel assembly. This will allow the covers to be closed with a fuel assembly loaded on the FAHS if the FAHS is moved to the Park position.

Could not test. SPHS crane and associated control screen was not installed at Test Area North.

Verify that lid/shield plug handling grapple cannot be disconnected as long as the cables are loaded.

Verify that the fuel assembly cannot be lowered while the rotating platform is in motion.

Verify that the crud catcher cannot be opened while the rotating platform is in motion.

Verify that the receiving cask transfer confinement port cover cannot be locked unless the port cover is in the open position.

Verify that the fuel assembly handling crane carriage (bridge and trolley) cannot be moved unless the receiving cask and source cask transfer confinement port covers are locked in the open position.

Verify that the source cask transfer confinement port cover cannot be locked unless the port cover is in the open position.

New Receiving cask lid/shield plug-handling grapple cannot be disconnected if the cables are loaded.

New Source or receiving cask transfer confinement port covers cannot be unlocked or moved if the FAHS crane is not in the Park position.

Not required by EPRI TP, added to support final design.

Not required by EPRI TP, added to support final design. 
Table A-2. (continued).

\begin{tabular}{|c|c|c|}
\hline $\begin{array}{l}\text { EPRI Test } \\
\quad \text { Plan } \\
\end{array}$ & Description, from EPRI Design & $\begin{array}{l}\text { Comment, Demonstration System } \\
\text { Deviations from the EPRI Design }\end{array}$ \\
\hline New & $\begin{array}{l}\text { Source and receiving transfer } \\
\text { confinement port covers cannot be } \\
\text { opened unless the crud catcher is } \\
\text { closed. }\end{array}$ & Not required by EPRI TP, added to support final design. \\
\hline New & $\begin{array}{l}\text { Crud catcher cannot be opened unless } \\
\text { the FAHS is over a port. }\end{array}$ & Not required by EPRI TP, added to support final design. \\
\hline New & $\begin{array}{l}\text { Crud catcher cannot be opened unless } \\
\text { the FAHS source and receiving port } \\
\text { covers are open. }\end{array}$ & Not required by EPRI TP, added to support final design. \\
\hline
\end{tabular}

\section{REFERENCE}

Dawson D. M., G. Guerra, T. Neider, and P. Shih, 1995, Dry Transfer System for Spent Fuel: Project Report, EPRI TR-105570, Electric Power Research Institute, Palo Alto, California. 
Appendix B

\section{Dry Transfer System Demonstration Test Plan}




\section{Appendix B \\ Dry Transfer System Demonstration Test Plan \\ OBJECTIVE}

The objectives of the dry transfer system demonstration (DTS) are to (1) determine that the DTS equipment works as intended (2) determine if the design meets current requirements and is adequate, (3) determine if the system can adequately recover from off-normal conditions, and (4) provide information on loading cycle time and overall system throughput rate. Additional benefits of the demonstration include (1) development of economic credibility for key elements of the design by actual purchase of engineered equipment and control systems, (2) advancement of portions of the current DTS design to the next level of detail through lessons learned in the fabrication, installation, and demonstration of the system, (3) provision of sufficient information to prompt a hot demonstration (through DOE at INEEL's Test Area North or a field demonstration at a utility's nuclear plant), and support for the DTS licensing effort.

\section{SCOPE}

The demonstration is to include all hardware, related control systems, and interlocks for the shield plug/lid handling subsystem, fuel assembly handling subsystem, cask interfacing subsystem, and the closed-circuit television and lighting system. The demonstration will be done in the TAN Warm Shop using a space frame to support the test components. The scope of the cold demonstration project includes functional testing from cask opening, through fuel transfer, and cask closing operations. Part of the demonstration is to include the complete series of tests from source cask receipt/ opening through fuel transfer and to receiving cask closing. The tests will include both normal operations and recovery from abnormal events. Cask and fuel mockups will be employed.

The demonstration will not include the receiving and source cask transfer subsystem, HVAC subsystem, radiation monitoring subsystem, receiving cask lid handling subsystem, decontamination subsystem, cask transport and lifting subsystem, lighting subsystem, cask vacuum/inerting/leak test subsystem, canister welding subsystem, and the DTS power subsystem. No demonstration will be made or simulated for the interlocks associated with the subsystems excluded from the demonstration (listed in the previous sentence). For the demonstration, an existing overhead crane will be substituted for the receiving cask shield plug/source cask lid handling subsystem with its dedicated upper crane subsystem, protective cover, and upper shield port covers. However, the overlid grapple portion of the shield plug/lid handling subsystem, modified to interface with the Warm Shop crane, will be included. Also, for purposes of demonstration, the concrete support structure and sliding shield door will be replaced by a space frame. The cask trolleys, shield door, and associated locks and interlocks will not be demonstrated.

INEEL will have responsibility for all procurement, test preparation, hardware assembly, acceptance testing, demonstration, and reporting activities. EPRI, or its designated representatives, will review and comment on the test procedures. Reporting activities will include all aspects of the procurement, hardware description, acceptance testing, and demonstration. Component and subsystem assembly and acceptance testing will have been performed, to the extent practicable, at the vendor's fabrication facility before shipment. INEEL will have addressed safety concerns before the start of testing. The various subsystems and components will be integrated at INEEL and tested before the demonstration, and INEEL will have prepared demonstration procedures before the demonstration. The test procedures will identify all systems to be tested and the design of site-specific hardware needed to carry out the demonstration. INEEL will prepare all tools needed to facilitate the demonstration of 
normal and recovery operations. The demonstration will use a three-quarter-length dummy LWR fuel assembly. INEEL will evaluate the potential impact of the lighter dummy fuel assembly on the validity of fuel assembly handling subsystem performance.

EPRI, DOE-ID, and DOE-HQ are to be informed of the testing schedule. DOE-ID, DOE-HQ, EPRI, their representatives, and the Utility Oversight Committee members are to be given the right to monitor actual testing. Before the conclusion of the cold demonstration, INEEL will evaluate the potential for hot demonstration in the TAN Hot Shop. At appropriate times during the testing and at the conclusion of the testing, EPRI is to have access to all test data and information. It is anticipated that the demonstration will result in a report written by DOE-ID and a separate report written by EPRI.

\section{PREREQUISITES OF THE TEST}

Before shipment of components to INEEL for installation at INEEL's TAN, equipment will be checked out at the vendors'/suppliers' facilities. Documentation of those tests shall be included in the INEEL DTS demonstration data package. These tests should conform to appropriate QA requirements per the procurement contracts. The QA requirements and confirmation of conformance to QA requirements are also to be included in the INEEL DTS demonstration data package. The total checkout of the control system cannot be conducted until it arrives at the INEEL and is integrated with the cask interfacing subsystem and the shield plug/lid handling subsystem. Before demonstration of the DTS system at INEEL, the equipment will be shipped to INEEL and installed at TAN. INEEL is to prepare and receive approval of appropriate safety documentation. The demonstration is to be performed to appropriately prepared, reviewed, and approved test procedures that are responsive to this test plan. The test procedures are to be prepared by the INEEL and EPRI or its representative is to be included in the review of the test procedures.

The components that compose the DTS to be demonstrated at INEEL's TAN are divided into five subsystems. FDI has procured four of these subsystems for INEEL. The subsystems and their respect suppliers are listed in Table B-1. Each subsystem is to undergo a performance test at the supplier's facility before being shipped to INEEL for installation as part of an integrated system. The performance test for the demonstration control system is to include checks on the support software and operational tests of the system. The operational tests will include end-to-end integrity checks and tests for each field input and output using external simulators as needed. The logic for each subsystem will be checked on a stand-alone basis and with all of the other systems operating.

Table B-1. Subsystems and suppliers.

\begin{tabular}{ll}
\multicolumn{1}{c}{ Subsystem Description } & \multicolumn{1}{c}{ Supplier } \\
\hline Demonstration Control Subsystem & Vision Engineering \\
& Cypress, CA \\
Fuel Assembly Handling Subsystem & NES, Inc. \\
& Danbury, CT \\
Shield Plug/Lid Handling Subsystem & Alpha Engineering \\
& Pocatello, ID \\
Cask Interface Subsystem, Mezzanine, and & American Fab \\
Support Frame & Idaho Falls, ID \\
Closed Circuit Television and Lighting Subsystem & LMI transfer confinement \\
\hline
\end{tabular}


The fuel assembly handling subsystem (FAHS) is to be functionally tested at the supplier's facility before shipment to INEEL. INEEL will provide the demonstration control system to the supplier to be used in the testing. The supplier will assemble the control system and the FAHS equipment to perform an integrated functional test. Control functions and interlocks that apply to DTS equipment other than the FAHS need not be tested at the supplier's facility. However, interlocks from other DTS equipment that effect FAHS control functions will be tested. The functional tests will include tests of the fuel handling grapple and the fuel handling crane for functional and load handling capabilities. Functional tests of the FAHS are to demonstrate the operability of all drives, actuators, limit switches, failure modes, and other active features. The hoisting mechanism is to be actuated between the maximum height and a position sufficiently low that the fuel handling grapple and load block are completely below the open crud catcher.

The testing of shield plug/lid handling subsystem (SPHS) is to include calibrations of the load cell and functional and proof testing of the overlid grapple assembly and its sensors and load cells. The proof tests and calibration of the load cells are performed at/by the manufacturer. The overlid grapple fingers are to be operated through their full range using grapple drives and manual operation. The cask overlid assemblies are to be functionally tested and load tested. The overlid fingers are to be put through their full range of motion.

A functional and proof test of the cask interfacing system is to be performed. The functional tests will be performed to demonstrate the adequacy and setup of linear actuators, rotary limit switches, linear actuator rod position potentiometers, load cells, bellows, and cask interfacing assembly self-alignment. The proof tests will be performed to demonstrate the capability of the linear actuators to retract and expand the cask interfacing assembly with a test load centered on top of the annular platform. A functional and proof test of the port cover system is to be performed. The functional test is to be performed to demonstrate the adequacy and setup of linear actuators, rotary limit switches, torque limiting couplings and port cover displacements. The proof test is to be performed to confirm the capability of the linear actuators to open and close the port covers with a test load, which meets or exceeds the maximum normal operating load, resting on top of the covers. Functional tests will be performed on the port cover lock pin system to demonstrate the adequacy and setup of linear actuators, rotary limit switches, and linear actuator rod position potentiometers.

No proof tests will be performed at INEEL. This is a one-time test performed at $300 \%$ of design load, and it will be performed at the manufacturer's facility. Lifting equipment used at INEEL will comply with requirements for periodic operational tests at $125 \%$ of their rated load.

\section{DEMONSTRATION TESTS}

\section{DTS Demonstration Control System}

The procurement package for the demonstration control system provides for checkout of the system at the vendors facilities using simulated control signal inputs. After checkout at the vendor's facility, the control system is to be shipped to the supplier of the fuel assembly handling subsystem to be available for the check out of that system. Both systems will be shipped to INEEL after successful completion of initial testing at the vendor's locations. The vendor tests are to be run again after the control system is installed at INEEL. The control system will not have been used with the shield plug, lid handling, and cask interface equipment with their associated interlocks.

During the DTS demonstration, the control system is to be extensively tested using the hardware and their sensors. Controls, alarms, and interlocks are to be tested and verified for each item listed in the remainder of this subsection. It is expected that the control system will operate as designed. The tests will be considered successful if control can be made to operate as expected, if all of the alarms and 
interfaces perform correctly, and if the control system is stable, i.e., does not lock up or crash. During the demonstration, a step-by-step control system log of the actions, responses, alarm initiations, clearing of alarms, etc., is to be maintained as part of the demonstration data. This log is to contain narrative concerning successes, failures, lessons learned, improvements needed, work-arounds used, etc.

It must demonstrate that the alarms listed below honor appropriate delay times (response times based on the manufacturer's design), are operational and can be acknowledged and reset from the applicable alarm pushbuttons on the touch screen display. The alarms are to be activated by creating the condition that activates the alarm. Demonstrate that the alarm cannot be canceled until the activating condition is removed. All alarms are expected to have an audible and flashing alarm indication on the CRT display.

- $\quad$ Emergency pushbutton activated (main control room)

- $\quad$ Emergency pushbutton activated (remote terminal room)

- $\quad$ Programmable logic controller hardware malfunction

- $\quad$ Cask interfacing jack not extended (jacks 1,2,3, source and receiving)

- $\quad$ Cask interfacing jack not retracted (jacks 1,2,3, source and receiving)

- $\quad$ Cask interfacing load cell exceeded maximum allowable weight

- $\quad$ Jack will not seat (jacks 1,2,3, source and receiving)

- $\quad$ Cask interfacing load cell exceeded minimum allowable weight

- $\quad$ Transfer confinement port cover will not open (source and receiving)

- Transfer confinement port cover will not close (source and receiving)

- Transfer confinement port cover will not lock (source and receiving)

- $\quad$ Transfer confinement port cover will not unlock (source and receiving)

- $\quad$ Receiving cask lockpin position malfunction

- $\quad$ Source cask lockpin position malfunction

- $\quad$ Overlid grapple will not open

- $\quad$ Overlid grapple will not close

- $\quad$ Cask overlid cover will not close

- Cask overlid cover will not open

- Grapple weight malfunction

- Transfer confinement port cover motor contactor failed to close 
- Cask interfacing motor contactor failed to close

- $\quad$ Fuel handling motor contactor failed to close

- $\quad$ Fuel handling crane will not position properly

- Overlid grapple weighing system malfunction

- Fuel handling crane hoist/grapple control malfunction

- $\quad$ Bridge overtravel alarm

- $\quad$ Bridge undertravel alarm

- $\quad$ Trolley overtravel alarm

- $\quad$ Trolley undertravel alarm

- $\quad$ Fuel load overtravel high

- $\quad$ Fuel load overtravel low

- $\quad$ Fuel load overweight

- $\quad$ Fuel load underweight

- Main hoist overspeed

- Main hoist rope unlevel wind

- $\quad$ Backup hoist rope unlevel wind

- $\quad$ Backup hoist overspeed.

It must demonstrate that the on-line diagnostic tests correctly identify and isolate faults for on-line and off-line hardware and software, and demonstrate that the software will ignore inputs when two or more buttons have been touched simultaneously.

It must demonstrate that interlocks are operational, operate as expected, and cannot be over-ridden during normal operation. As a minimum, the following interlocks are to be demonstrated:

- Verify that the fuel assembly handling crane carriage (bridge and trolley) cannot be moved unless the crud catcher is closed and the fuel assembly grapple is in its upper z position.

- Verify that the rotating platform cannot be moved unless the crud catcher is closed and the fuel assembly grapple is in its upper $\mathrm{Z}$ position.

- Verify that the grapple of the fuel assembly handling hoist system cannot be lowered unless the crud catcher is open. 
- Verify that the transfer confinement port cover cannot be unlocked or moved when the fuel assembly handling crane carriage is in motion.

- Verify that the crud catcher cannot be opened when the fuel assembly handling crane carriage is in motion.

- Verify that the crud catcher cannot be closed unless the fuel assembly grapple is in its upper $\mathrm{z}$ position.

- Verify that the fuel assembly grapple cannot be lowered when the fuel assembly handling crane carriage is in motion.

- Verify that a fuel assembly cannot be lifted if the fuel assembly handling grapple is not totally connected or disconnected.

- Verify that the receiving and source cask transfer confinement port covers cannot be unlocked or closed if the fuel assembly handling grapple is engaged.

- Verify that the fuel assembly cannot be removed from the grapple unless the grapple is in the proper position and the hoist is unloaded.

- Verify that the transfer confinement port covers cannot be unlocked or moved when the fuel assembly handling hoist is loaded.

- Verify that the lid/shield plug handling grapple cannot be lifted unless the grapple is fully connected or fully disconnected.

- Verify that the lid/shield plug handling grapple cannot be disconnected as long as the cables are loaded.

- Verify that the fuel assembly cannot be lowered while the rotating platform is in motion.

- Verify that the crud catcher cannot be opened while the rotating platform is in motion.

- Verify that the receiving cask transfer confinement port cover cannot be locked unless the port cover is in the open position.

- Verify that the fuel assembly handling crane carriage (bridge and trolley) cannot be moved unless the receiving cask and source cask transfer confinement port covers are locked in the open position.

- Verify that the source cask transfer confinement port cover cannot be locked until the port cover is in the open position.

The functionality and repeatability of sensors are to be checked. In particular, position sensors for the fuel assembly handling subsystem are to be checked for their ability to determine the absolute position of bridge, trolley, and rotating platform. In addition, sensors should give the position and load readings for the fuel assemblies as they are being extracted from and put into the casks. 


\section{Fuel Assembly Handling Subsystem}

Functional and load tests will have been performed on this equipment before it being shipped to INEEL. Proof load tests performed at the manufacturer will not be repeated at the INEEL. Functional tests should be repeated at INEEL followed by additional testing to determine turn around time, alignment functionality, positioning capability, and recovery from off-normal events. As part of the alignment and positioning capability, notation shall be made of the ability of the fuel assembly handling subsystem to index on the two casks (learn and retain basket fuel slot locations) to permit rough positioning before fuel assembly extraction/placement.

A typical load cycle for transfer of one fuel assembly consists of the following steps:

- $\quad$ Position the fuel-handling crane with empty grapple over the source cask (fast bridge, trolley and rotation speed).

- $\quad$ Open and lock the transfer confinement port covers. Using the closed-circuit TV, visually monitor opening of port covers before locking them. Switch off power to the port covers.

- $\quad$ Accurately position the fuel handling crane grapple over the desired source cask fuel assembly position (slow bridge, trolley and rotation speed).

- $\quad$ Open the crud catcher and lower the fuel handling grapple (fast hoisting speed). Check the open position of the crud catcher with the closed-circuit TV.

- Accurately position the grapple (slow bridge, trolley, rotation and hoisting speed) and latch onto the fuel assembly.

- $\quad$ Lift the fuel assembly out of the source cask and into the fuel handling crane fuel tube (slow hoisting speed). Monitor the grapple loading during extraction from the cask (fuel assembly weight and frictional resistance). Monitor $\mathrm{Z}$ position and cable loading during lifting. The operation should automatically stop when the grapple has reached its upper $\mathrm{Z}$ position.

- Close the crud catcher. Check the closed position of the crud catcher using the closed-circuit TV.

- Accurately position the fuel handling crane loaded with the weight of the fuel assembly over the receiving cask (fast and slow bridge, trolley and rotation speed).

- $\quad$ Open the crud catcher. Check the open position of the crud catcher with the closed-circuit TV.

- $\quad$ Lower the fuel assembly into the receiving cask (slow hoisting speed). Release the fuel assembly.

- $\quad$ Raise the empty fuel handling grapple (fast hoisting speed). Close the crud catcher. Check the closed position of the crud catcher using the closed-circuit TV.

The above process or one similar to it is to be repeated a minimum of three times. Data is to be taken to record the time duration of completing a complete cycle of moving a fuel assembly from one cask to another. Data is to be taken to determine positioning accuracy. Tests are to be conducted to 
determine positioning repeatability of the fuel handling equipment. Tests are to be conducted to determine the effect of maximum misalignment (displacement and rotational) of the source and receiving cask. Equipment specifications allow misalignment of cask center lines by up to $7.6 \mathrm{~cm}$ (3.0 inches) and rotational misalignment of the basket grid significantly greater than one degree. Record the time for moving fuel between aligned baskets and for moving fuel between misaligned baskets. Make notation of the relative ease associated with moving fuel between misaligned baskets. Perform tests to determine the positional accuracy of the FAHS bridge and trolley. Demonstrate that the fuel assembly grapple can reach down $20.3 \mathrm{~cm}$ (8 inches) into a cask to pick up a fuel assembly. Make notation of the effectiveness of the audible signal system that should be operational during any movement of the fuel handling crane bridge or trolley. After the last fuel assembly has been moved, the fuel assembly handling crane carriage is to be placed in a parked position. Functioning of interlocks shall be addressed as part of the demonstration of the functionality of the control system.

\section{Shield Plug/Lid Handling Subsystem}

The tests for the SPHS are to consist of a functional test with a load of the grapple assembly, its sensors and load cells. The calibration of the load cell is to be checked. The grapple fingers are to be operated through their full range using grapple drives and manual operation. The cask overlid assemblies are to be functionally tested and load tested. The overlid fingers are to be put through their full range of motion. During the proof test at the manufacturer, the equipment will be loaded to $300 \%$ of normal operating loads.

A demonstration of remote removal, handling and installation of cask shield plugs is to be performed. The motorized grapple and the overlids will be used at the Test Area North facility for remote handling of the cask shield plugs with an existing overhead crane. A demonstration will be provided to show how the grapple engages and handles the shield plugs to protect the upper surface of the shield plugs from radioactive contamination. Initially, the overlid is to be supported in the opening of an annular platform with the gripper fingers fully opened. The shield plug, with a pintle attached, is to be positioned under the overlid such that the overlid seals are interfaced with the shield plug and the open gripper fingers surround the pintle. The grapple, attached to the crane hook with the grapple fingers fully open, is to be interfaced with the overlid grapple receptacle. The grapple sensor system is to be checked to see that it indicates when the grapple is fully seated on the overlid. The grapple linear actuator is to be operated so the grapple fingers lock the grapple to the overlid. The grapple sensor system will be checked to see it indicates when the grapple fingers are fully closed. The grapple gear motor and drive shaft system are to be operated to turn the drive screw in the overlid to close the gripper fingers around the shield plug pintle. The system is to be slightly raised so they are not supported by the annular support plate. This will provide a demonstration of the load train. Verify firm attachment of the grapple to the overlid and the overlid to the test fixture pintle. Release the load and test fixture from the overlid and release the overlid from the grapple.

\section{Cask Interface Equipment, Mezzanine, and Support Frame}

The cask interfacing system consists of four mezzanine plates that will be bolted to the support frame. The receiving and source cask interfacing systems with their actuators and controls are to be affixed on the underside of the mezzanine plates. The functionality of the cask interfacing system is to be demonstrated. This includes the setup of linear actuators, rotary limit switches, linear actuator rod position potentiometers, load cells, bellows and cask interfacing assembly self-alignment. Demonstrate that:

- The limit switches trip 1/4 in. away from the linear actuator extreme position. 
- The bellows hold their shape when performing their function.

- The cask interfacing assembly can self-align about the linear actuator vertical axis between $11 / 2$ and $21 / 2$ degrees.

- Demonstrate that the cask port covers travel freely between the open position with the access opening clear and the closed position with the access opening covered.

- The port cover clears the top of the mezzanine plate by $1 / 4$ in. maximum. Tests shall be conducted with a load to simulate the weight of the plug/lid on the port cover (proof test at the manufacturer). The weight shall be sufficient to validate performance.

- When closed, the port covers will cover and straddle the mezzanine plate openings.

- When open, the port covers will completely clear the mezzanine plate openings and be within the mezzanine plate limits.

- Torque limiting couplings for the port cover actuators release at a torque of no more than $130 \%$ of the maximum required operating torque.

- Inside the guiding rails, the port cover supporting wheels will have vertical clearance between $1 / 8$ and $3 / 8$ in.

- Inside the guiding rails, the port cover guiding wheels will have a lateral clearance between $1 / 16$ and $3 / 16$ in.

- The linear actuators for the port covers are functional when a test load rests on the top of the port cover. The test load for the receiving cask port cover is 17,000 pounds, and for the source cask port cover is 5,500 pounds.

- The port cover lock pin system operates adequately and that it can be reached and unlocked manually.

\section{Closed-Circuit Television and Lighting Subsystem}

The closed-circuit television (CCTV) and lighting system provides feedback to the operator needed for remote operation and will help with recovery from accidents, and off-normal events. The demonstration will provide information for the following activities:

- An evaluation shall be made to determine whether the CCTV system will be able to monitor the cask/bellows interfacing operation, if it can identify sealing of the bellows against the top of the cask, and if it can provide enough information to determine when the bellows are sealed or removed from the cask.

- $\quad$ The CCTV will be used during fuel transfer to locate and align the fuel handling equipment with the fuel baskets. The ease and accuracy of the positioning and aligning the fuel handling equipment with the fuel baskets should be determined.

- $\quad$ The CCTV will be used to provide confirmation of lid location and locking status of the port covers. 
- $\quad$ The demonstration will be helpful in identifying blind spots and in possible elimination of the blind spots by selection of camera mounting locations.

- $\quad$ The CCTV will be use to determine the crud catcher position.

\section{Off-Normal Event Recovery}

During the demonstration, the following activities shall be conducted to demonstrate recovery operations if there is a power failure or equipment failure. Where long reach tools are used in off-normal event recovery, they are to be demonstrated at full length.

- There should be a demonstration of the ability manually to move the FAHS equipment in the $\mathrm{x}$-direction, the y-direction, and rotationally using long-reach tools through simulated penetration in the shielded structure walls.

- Demonstrate remote manual handling of the grapple, overlid, and test fixture using manual handling tools that can be actuated from outside the DTS structure.

- Demonstrate that the port covers can be actuated manually using special tools.

- Demonstrate recovery from power failure during the extraction or placement of a fuel assembly. The demonstration includes using manual tools to recovery from a partially withdrawn fuel assembly. The demonstration should include the manual movement of a fuel assembly from one cask to the other, the returning of a fuel assembly to the source cask, or placement of a fuel assembly in the receiving cask. The demonstration should also include the manual placement of a fuel assembly simulating recovery from a power failure with a fully withdrawn fuel assembly contained in the fuel-handling machine when the machine is located between casks when both casks have fuel in them.

- Demonstrate that the FAHS hoist drive system ensures that a single failure of any hoist mechanism component, including the consequential damage resulting from the initial single failure, will not result in the release of the lifted load and will not result in uncontrolled movement of the lifted load.

- Demonstrate recovery from a jammed crud catcher or a faulty crud catcher actuator with a fuel assembly in the fuel tube. Assume crud has interfered with the operation of the crud catcher.

- Demonstrate removal of a foreign object from the rails of the port cover or from the fuel handling system where the foreign object is interfering with movement of the port cover or fuel handling equipment.

\section{DOCUMENTATION}

As part of the procedure development, the INEEL is to establish a documentation matrix that lists each test or test sequence to be performed and the associated documentation for each. The type and level of documentation shall be based on the function and classification of the system, component, or operation being tested or demonstrated. Documentation can be in the form of hard copy, computer disk, and/or videotape. A video record shall be made of a complete sequence initial receipt of a cask, through fuel 
transfer and closing of the cask, to cask removal. The INEEL is to establish a comprehensive identification and tracking system to permit the filing, cataloging, and retrieval of test documents.

Specific reference should be made to the requirements in DOE/RW/0333P in the following sections: Section 5-Document Control, Section 7-Purchased Items and Services (as applicable to the tests performed by the vendors), Section 10-Inspection (as applied to load tests, Section 11-Test Control, Section 12-Control of Measuring and Test Equipment, Section 14-Inspection, Test, and Operating Status, and Section 17-Quality Assurance Records, and Supplement-Software.

Documentation storage will be by the contractor until otherwise directed. Appropriate storage protection will be implemented to preserve the documents.

\section{EXPECTED RESULTS/ACCEPTANCE CRITERIA}

It is anticipated that initial operation of the system may uncover potential flaws in equipment or logic that requires modification to operate properly. It is anticipated that modification may need to be made to the control system. These are considered acceptable if they can be resolved during the cold testing in the warm shop. The demonstration will be considered acceptable if it is conducted according to approved procedures that address the items contained in this test plan. The TMC will have an opportunity to review and comment on the test procedures prior to their implementation.

\section{TEST PLAN MODIFICATIONS}

This test plan outlines tests to be performed in the demonstration of the dry transfer system. It sets forth the overall intent and objectives of the demonstration. If the demonstration identifies items not adequately addressed by this test plan, modification will be made to this test plan to adapt to those items. The new items will be addressed by the Technical Management Committee and may be incorporated if the additional testing can be held within budgetary constraints. A revision to the test plan requires the same level of approval as the original test plan.

\section{QUALITY ASSURANCE REQUIREMENTS}

The work described in this test plan shall comply with a Quality Assurance Program that complies with the following requirements:

- $\quad$ Title 10 of the Code of Federal Regulations (CFR), Part 72.140, Subpart G, Quality Assurance

- $\quad$ Office of Civilian Radioactive Waste Management “OCRWM Quality Assurance Requirements and Description," DOE/RW-0333P, Rev. 5, with exceptions or where requirements are not applicable based on scope of the work are to be explicitly noted by INEEL. 
B-12 


\section{DISTRIBUTION}

\section{OFFSITE}

Office of Scientific and Technical Information ( 10 copies)

U.S. Department of Energy

175 Oak Ridge Turnpike

Oak Ridge, TN 37830

D.E. Shelor

Office of Civilian Radioactive Waste Management

U.S. Department of Energy, RW-40

1000 Independence Avenue, SW

Washington, DC 20585

J. R. Williams

Office of Civilian Radioactive Waste Management

U.S. Department of Energy, RW-46

1000 Independence Avenue, SW

Washington, DC 20585

L. Stewart (10 copies)

Office of Civilian Radioactive Waste Management

U.S. Department of Energy, RW-40

1000 Independence Avenue, SW

Washington, DC 20585

A. R. Griffith (5 copies)

Office of Environmental Management, EM-21

U. S. Department of Energy

Germantown, MD 20874-1290

M.A. McKinnon (10 copies)

Pacific Northwest National Laboratory

Battelle Boulevard, MSIN:K8-34

Richland, Washington 99352

A.J. Machiels (10 copies)

Electric Power Research Institute

P.O. Box 10412

Palo Alto, CA 94303-0813

R. W. Lambert

Electric Power Research Institute

P.O. Box 10412

Palo Alto, CA 94303-0813

R. H. Jones, P.E.

P. O. Box 1510

Los Gatos, CA 95031-1510 
D.W. Kane

Yucca Mountain Site Characterization Office

U.S. Department of Energy B-HL/R-414

1261 Town Center Drive

Las Vegas, NV 89134

B. J. Verna

Yucca Mountain Site Characterization Office

U.S. Department of Energy B-HL/R-423

1261 Town Center Drive

Las Vegas, NV 89134

D.C. Langstaff

U. S. Department of Energy

Richland Operations Office, B-267/R-324

P.O. Box 550

Richland, WA 99352

R. Jones (5 copies)

Sacramento Municipal Utility District

14440 Twin Cities Road M/S N-505

Herald, CA 95638-99799

T. Bernacki (5 copies)

NES, Inc.

44 Shelter Rock Road

Danbury, CT 06810

J.A. Gago Badenas

ENRESA

Emilio Vargas, 7

28043 Madrid, Spain

R. C. Bowser

BNFL Inc

10306 Eaton Place, Suite 450

Fairfax, VA 22030

P. Dyck

International Atomic Energy Agency

Wagramer Strasse 5, P. O. Box 100

A-1400 Vienna, Austria

E.R. Johnson (5 copies)

JAI Corporation

413 Chain Bridge Road, Suite 200

Fairfax, VA 22030

F. Marcheix

Air Liquide Engineering

57, avenue Carnot - BP 313

94503 Champigny-sur-Marne

Cedex France 
T. Neider (5 copies)

Transnuclear, Inc

Four Skyline Drive

Hawthorne, NY 10532-2120

H. L. Rothstein

Raytheon Nuclear Inc.

508 Carnegie Center

CN 5287

Princeton, NJ 08543-5287

E.M. Supko

Energy Resources International, Inc.

1025 18th Street, NW, Suite 500

Washington, DC 20036

\section{ONSITE}

Idaho National Engineering and Environmental Laboratory

D.C. Koelsch (10 copies)

U. S. DOE-ID

MS-1154

850 Energy Drive

Idaho Falls, ID 83401-1563

B. A. Beller

U. S. DOE-ID

MS-1154

850 Energy Drive

Idaho Falls, ID 83401-1563

M.R. Christensen (5 copies)

BBWI

MS-9208

PO BOX 1625

IDAHO FALLS ID 83415 - 9208

Joe Gili

BBWI

MS-9208

PO BOX 1625

IDAHO FALLS ID 83415 - 9208

Walt Bare

BBWI

MS-9208

PO BOX 1625

IDAHO FALLS ID 83415 - 9208 